\title{
Manipulation and the Allocational Role of Prices
}

\author{
ITAY GOLDSTEIN \\ University of Pennsylvania \\ and \\ ALEXANDER GUEMBEL \\ Saïd Business School and Lincoln College, University of Oxford
}

First version received February 2004; final version accepted May 2007 (Eds.)

\begin{abstract}
It is commonly believed that prices in secondary financial markets play an important allocational role because they contain information that facilitates the efficient allocation of resources. This paper identifies a limitation inherent in this role of prices. It shows that the presence of a feedback effect from the financial market to the real value of a firm creates an incentive for an uninformed trader to sell the firm's stock. When this happens the informativeness of the stock price decreases, and the beneficial allocational role of the financial market weakens. The trader profits from this trading strategy, partly because his trading distorts the firm's investment. We therefore refer to this strategy as manipulation. We show that trading without information is profitable only with sell orders, driving a wedge between the allocational implications of buyer and seller initiated speculation, and providing justification for restrictions on short sales.
\end{abstract}

\section{INTRODUCTION}

One of the most fundamental roles of prices is to facilitate the efficient allocation of scarce resources (Hayek, 1945). In secondary financial markets, prices are thought to play an allocational role because they convey information that improves the efficiency of real investment decisions. This allocational role of prices has been studied in papers by Leland (1992), Dow and Gorton (1997), Subrahmanyam and Titman (1999, 2001), Dow and Rahi (2003), and others.

In this paper we identify a limitation inherent in the allocational role of prices in financial markets. We show that the very fact that prices play an allocational role opens up opportunities for market manipulation. When such manipulation occurs, the information conveyed by prices is misleading, and this distorts resource allocation and reduces economic efficiency.

We model the allocational role of prices as follows. There is a firm that faces an investment opportunity with uncertain net present value (NPV). There is a speculator who may have information about aspects of this opportunity that are relevant for the optimal investment decision and that are not yet known to the firm. Such information could be about the project's appropriate cost of capital, future demand in the economy, or the firm's position relative to its competitors. When the speculator is informed, he optimally chooses to trade in the firm's stock based on his information. Specifically, he sells the stock when he has negative information and buys it when he has positive information. The trading process is modelled in a market microstructure setting based on Kyle (1985). As in Kyle (1985), the information of the speculator gets partially reflected in the stock price. Extending Kyle (1985), in our model, the information in the price is then optimally taken into account by the firm in its investment decision. This complicates the equilibrium analysis considerably, because the price and the real value of the firm are essentially interdependent and determined endogenously. 
Our main result is that the feedback effect from the financial market to the real investment decision generates equilibria where the speculator sells the stock even when he happens to be uninformed. When he does that, he reduces the informativeness of the price and the efficiency of the resulting investment decision. Selling in the absence of information is profitable in our model for two reasons. First, the price quoted by the market maker reflects the possibility that the speculator is informed and that the market will improve the efficiency of the investment decision and increase the value of the firm. When the speculator knows that he is, in fact, uninformed, he knows that the market will not improve the allocation of resources. Thus, he can sell at a price that is higher than the expected value (conditional on him knowing that he is uninformed). Second, the speculator can profit from the effect that his trade will have on the firm's investment decision. In particular, he can profit by establishing a short position in the stock and subsequently driving down the firm's stock price by further short sales. The firm will infer that the lower price may reflect negative information about the investment opportunity and therefore will not invest. On average this is the wrong decision and will in itself reduce the value of the firm. This enables the speculator to cover his short position at a lower cost and make a profit. Due to the nature of this strategy, we refer to it as manipulation.

Manipulation occurs in our model if information conveyed by selling pressure in the financial market is sufficient to lead to cancellation of the investment project. This strong feedback effect will exist when (i) the ex-ante NPV of the investment is not too high; (ii) the uncertainty regarding the outcome of the investment is large; or (iii) the firm expects that useful information is likely to come from the financial market. Thus, in such cases, our model predicts a large selling pressure followed by cancellation of investment projects. Interestingly, we show in the paper that when the feedback effect from the financial market to the real economy is very strong, all equilibria of the trading game will feature manipulation.

Finally, we show that manipulation is profitable only via sell orders. This is because the two sources of profit behind the manipulation strategy, as described above, cannot generate profits with buy orders. First, the allocational role of prices always increases the value of the firm in expectation. Thus, conditional on being uninformed, the speculator expects that the value of the firm is lower than what is reflected in the market price. This creates an incentive for him to sell, not to buy. Second, while the speculator can potentially manipulate the firm's investment decision with either buy orders or sell orders, this will only be profitable with sell orders. Buying the stock with no information will lead to overinvestment, which will only decrease the value of the speculator's accumulated long position. This is because overinvestment-just like underinvestment-is inefficient and leads to a reduction in firm value. Thus, the speculator can benefit from manipulating the price and distorting the real investment decision only when he accumulated a short position. An interesting implication from this is that there is asymmetry between buy orders and sell orders. As a result, sell orders are less informative about the fundamentals, and the response of the price to sell orders is less strong.

In our model, the feedback effect is generated by managers learning from the stock price when taking investment decisions. This mechanism has received empirical support in the recent work of Durnev, Morck and Yeung (2004), Luo (2005), and Chen, Goldstein and Jiang (2007). ${ }^{1}$ It is important to note, however, that learning by managers is not necessary for our results. Alternatively, feedback may arise from the effect of the stock price on the firm's access to capital

1. The assumption that stock-market participants have information about some aspects of the firm, which is not available to the firm's managers, is made in papers by Dow and Gorton (1997), Subrahmanyam and Titman (1999, 2001), Dow and Rahi (2003), and others. The initial public offering (IPO) literature has also used such an assumption in explaining the determinants of underpricing. See, for example, Rock (1986), Benveniste and Spindt (1989), Benveniste and Wilhelm (1990), and Biais, Bossaerts and Rochet (2002). 
(see Baker, Stein and Wurgler, 2003). In either case, prices play an allocational role, which is sufficient to generate our main result on manipulation.

Aside from identifying a fundamental limitation inherent in the allocational role of stock prices, our paper makes two other novel contributions. First, our paper contributes to the large debate on the role of short sales. In this debate, the asymmetry between seller-initiated speculation and buyer-initiated speculation is implicitly understood to be relevant, for example, by regulatory bodies (e.g. the securities and exchange commission (SEC) in the U.S.), who introduced restrictions on short sales such as the "up-tick" rule, and by many firms, who complain about the damage from massive short sales. ${ }^{2}$ Our paper is, to our knowledge, the first to point out a theoretical justification for such concerns. In a wider context, our model can be linked to recent episodes of currency attacks, where speculators drove down the price of a currency, which led to subsequent economic collapse and further depreciation of a country's currency. ${ }^{3}$ In the existing theoretical literature on currency speculation (e.g. Morris and Shin, 1998; Vitale, 2000) the underlying feedback mechanism has not received much attention, although practitioners appear to have a rudimentary understanding that it is crucial to episodes of currency attacks. ${ }^{4}$

Second, our paper identifies a new mechanism through which market manipulation can occur. In general, it is not straightforward to construct models where speculators make a profit from trading without information. As Jarrow (1992) points out, such trading strategies are not profitable in standard models because either (i) the speculator's trade will move the price in an unfavourable direction relative to subsequently revealed information, or (ii) when no further information is revealed, the speculator's attempt to unwind his original trade in a later date will have a symmetric price impact. In our model, such a trading strategy can be profitable because of the feedback effect that prices have on the underlying asset value. When an uninformed speculator acquires a position he knows that his trade affects the underlying asset value in a way that on average will enable him to unwind the position at a profit. A number of other papers consider the possibility of manipulative trading strategies that are not based on the feedback effect, but rather on specific features of the trading environment. ${ }^{5}$ They include Allen and Gale (1992), Allen and Gorton (1992), Kumar and Seppi (1992), Gerard and Nanda (1993), Vitale (2000), Chakraborty and Yilmaz (2004a,b), and Brunnermeier (2005).

Our paper is related to recent research that highlights the implications of the feedback effect from prices to real value. Khanna and Sonti (2004) show that feedback from prices to asset value can generate herding, like in Avery and Zemsky (1998). Assuming that a sequence of buy orders increases firm value in the good state of the world, they show that a late trader with an inventory of the stock will buy after receiving a negative private signal and observing a sequence of buy orders. Following previous trades, this trader believes that the state of the world is likely to be good and buys to increase the value of his inventory. Our results are different from those of

2. Many firms complain about short sales arguing that they may be manipulative and therefore costly to shareholders. For example, in a letter to the SEC, Medizone International Inc. estimates that the short interest in their stock at one point exceeded $50 \%$ of the public float. The company claims that "[...] short-selling, [...] and other actions that have served to limit our access to capital, diminished or suppressed the value of our shares [...]. This short selling has proven extremely detrimental to our company and our shareholders". http://www.sec.gov/rules/concept/s72499/marshal2.txt

3. See Corsetti, Pesenti and Roubini (2002) and Corsetti, Dasgupta, Morris and Shin (2004) for an assessment of the role of large traders in those crises. Cheung and Chinn (2001) provide survey evidence that large manipulative traders in FX markets play an important role.

4. For example George Soros (1994) argues that "Instead of fundamentals determining exchange rates, exchange rates have found a way of influencing fundamentals.[...] When that happens speculation becomes a destabilizing influence".

5. Allen and Gale (1992) distinguish further between action-based, information-based, and trade-based manipulation. We are only concerned with trade-based manipulation. In action-based manipulation an agent's action directly affects the value of an asset (e.g. Vila, 1989; Bagnoli and Lipman, 1996; and Ottaviani and Sorensen, 2007). This type of manipulation is usually illegal due to restrictions on insider trading. In information-based manipulation an agent can spread rumours or false information (e.g. Benabou and Laroque, 1992; and van Bommel, 2003). 
Khanna and Sonti (2004), particularly because in our model the feedback effect and the position of the trader are derived endogenously. In contrast to Khanna and Sonti (2004), the trader in our model trades with a view to distorting the firm's investment decision. This allows us to derive new results for allocational efficiency and the role of short sales in manipulation.

Hirshleifer, Subrahmanyam and Titman (2006) discuss the role of feedback in a model with irrational traders and show that such traders may survive in financial markets when their trades affect firm value. Attari, Banerjee and Noe (2006) explore trading by institutional investors around corporate control changes and point to the possibility of manipulation when a value enhancing action is taken by a large trader conditional on stock price movements. A price drop leads to increased firm value, because it triggers shareholder activism. This contrasts with our result where a price drop has a negative impact on firm value rendering manipulation profitable for sellers only.

The remainder of the paper is organized as follows: Section 2 presents the model set-up. In Section 3 we derive as a benchmark the equilibrium trading strategies when firm value is independent of stock price movements. Section 4 then introduces feedback and shows that manipulation arises in equilibrium. In Section 5, we analyse the possibility of equilibria without manipulation in the presence of feedback. Section 6 analyses the difference between seller-initiated and buyer-initiated manipulation and shows that the latter is not profitable. In Section 7 we consider the robustness of the manipulation equilibrium to the introduction of more strategic traders and to the endogeneity of liquidity trading. Section 8 concludes. All proofs are relegated to the Appendix.

\section{THE MODEL}

The model has four dates $t \in\{0,1,2,3\}$ and a firm whose stock is traded in the financial market. The firm's manager needs to take an investment decision. In $t=0$, a risk-neutral speculator may learn private information about the state of the world $\omega$ that determines the profitability of the firm's investment opportunity. Trading in the financial market occurs in $t=1$ and $t=2$. In addition to the speculator, two other types of agents participate in the financial market: noise traders whose trades are unrelated to the realization of $\omega$ and a risk-neutral market maker. The latter collects the orders from the speculator and the noise traders and sets a price at which he executes the orders out of his inventory. The information of the speculator may get reflected in the price via the trading process. In $t=3$, the manager takes the investment decision, which may be affected by the stock price realizations. Finally, all uncertainty is realized and pay-offs are made. We now describe the firm's investment problem and the trading process in more detail.

\subsection{The firm's investment problem}

Suppose that the firm has an investment opportunity that requires a fixed investment at the amount of $K$. The firm's manager acts in the interest of shareholders and chooses whether or not to invest with the objective to maximize expected firm value. Suppose also that the firm can finance the investment with retained earnings. The firm faces uncertainty over the quality of the available investment opportunity. There are two possible states $\omega \in\{l, h\}$ that occur with equal probabilities. We denote the value of the firm if it invests in the high state $\omega=h$ as $V^{+}$; the value of the firm if it invests in the low state $\omega=l$ is $V^{-6}$ Firm value can then be expressed as a function $V(\omega, k)$ of the underlying state $\omega$ and the investment decision $k \in\{0, K\}$ :

6. In a previous version of this paper the firm's value was derived endogenously based on a set-up where the firm could spend a sunk cost to enter a product market of uncertain size in which it would then be a monopolist. Firm value in such a set-up is increasing in market size. See, for example, Sutton (1991) for a model of this kind.

(c) 2008 The Review of Economic Studies Limited 


$$
\begin{gathered}
V(h, K)=V^{+}, V(l, K)=V^{-}, \\
V(\omega, 0)=0 .
\end{gathered}
$$

We assume that it is worth investing in the high state, but not in the low state: ${ }^{7}$

$$
V^{+}>0>V^{-} \text {. }
$$

The decision of the firm can be conditioned on the information $I_{\mathrm{F}}$ it has about the underlying state $\omega$. The firm may learn such information from the price of its equity in the financial market and/or from other sources. We now turn to describe the financial market.

\subsection{Trade in the financial market}

There is one speculator in the model. In $t=0$, with probability $\alpha$, the speculator receives a perfectly informative private signal $s \in\{l, h\}$ regarding the state of the world $\omega$. With probability $1-\alpha$ he receives no signal, which we denote as $s=\varnothing$. We will sometimes use the term "positively informed speculator" to refer to the speculator when he obtains the signal $h$. We will analogously use the terms "negatively informed speculator" and "uninformed speculator". Depending on his signal, the speculator may wish to trade in the financial market. There are two trading dates: $t=1,2$. In each trading date, the speculator needs to submit his order to a market maker. In addition to the speculator and the market maker, there is a noise trader in each trading date. Denoting the order of the noise trader in date $t$ as $n_{t}$, we assume that $n_{t}=-1,0$, or 1 with equal probabilities; that is, the date $t$ noise trader buys, sells, or does not trade with equal probabilities. Moreover, we assume that the noise traders' orders are serially uncorrelated, that is, $n_{1}$ and $n_{2}$ are independent. For now, we treat the noise traders' orders as exogenous. In Section 7.2, we endogenize their trading behaviour by introducing hedging motives. In each trading date, the speculator submits orders $u_{t}$ of the same size as the noise trader, or he does not trade at all; that is, $u_{t} \in\{-1,0,1\}$.

Following Kyle (1985), in each round of trade, orders are submitted simultaneously to a market maker who sets the price and absorbs order flows out of his inventory. The market maker sets the price equal to expected asset value, given the information contained in past and present order flows. This assumption is justified when the market making industry is competitive. The market maker can only observe total order flow $Q_{t}=n_{t}+u_{t}$, but not its individual components. Possible order flows are therefore $Q_{t} \in\{-2,-1,0,1,2\}$. In $t=1$, the price is a function of total order flow: $p_{1}\left(Q_{1}\right)=E\left[V \mid Q_{1}\right]$. In $t=2$, the price depends on current and past order flows: $p_{2}\left(Q_{1}, Q_{2}\right)=E\left[V \mid Q_{1}, Q_{2}\right]$.

In our model, the speculator can only submit market orders, that is, orders that are not contingent on current price. Thus, his order in $t=1$ is contingent only on his signal $s$. In addition to the signal, his order in $t=2$ may be contingent on the price in $t=1, p_{1}$, as well as on the position he acquired at that time, $u_{1}$. Note that $p_{1}$ is a function of the total order flow in $t=1$, $Q_{1}$. Thus, to ease the exposition, we assume that the speculator observes $Q_{1}$, and therefore can directly condition his $t=2$ trade on $Q_{1}$ instead of on $p_{1}$. Similarly, the firm manager observes $Q_{1}$ and $Q_{2}$, and may use them in his investment decision. The equilibrium concept we use is the Perfect Bayesian Nash Equilibrium. Here, it is defined as follows: (i) A trading strategy by the speculator $\left\{u_{1}(s)\right.$ and $\left.u_{2}\left(s, Q_{1}, u_{1}\right)\right\}$ that maximizes his expected final pay-off, given the price-setting rule, the strategy of the manager, and the information he has at the time he makes

7. To ease the exposition, we do not include the assets in place in the expressions for the value of the firm. Including the assets in place explicitly will, of course, not affect our analysis. 
the trade, (ii) an investment strategy by the firm that maximizes expected firm value given all other strategies, (iii) a price-setting strategy by the market maker $\left\{p_{1}\left(Q_{1}\right)\right.$ and $\left.p_{2}\left(Q_{1}, Q_{2}\right)\right\}$ that allows him to break even in expectation, given all other strategies. Moreover, (iv) the firm and the market maker use Bayes' rule in order to update their beliefs from the orders they observe in the financial market. Finally, (v) all agents have rational expectations in the sense that each player's belief about the other players' strategies is correct in equilibrium.

\section{EQUILIBRIUM IN A MODEL WITH NO FEEDBACK}

As a benchmark, we consider in this section the case where there is no feedback from the financial market to the firm's investment decision. We call the resulting game the "no-feedback game". Specifically, we assume that the firm is fully informed about the state of the world, and therefore invests when the state is high and does not invest when it is low. Thus, the investment decision in $t=3$ is not affected by the trading outcomes in the financial market in $t=1$ and $t=2 .{ }^{8}$

In the no-feedback game, the value of the firm is $V^{+}$when the state of the world is high and 0 when the state of the world is low. When the speculator is positively informed; that is, when $s=h$, he knows that the value of the firm is $V^{+}$. When the speculator is negatively informed, that is, when $s=l$, he knows that the value of the firm is 0 . Finally, when the speculator is uninformed, that is, when $s=\varnothing$, he does not know the value of the firm, but knows that in expectation it is $\frac{V^{+}}{2}$. The market maker also starts with the expectation that the value of the firm is $\frac{V^{+}}{2}$ and updates this expectation after every round of trade.

The existence of equilibrium in the no-feedback game can be easily shown with an example. In fact, we know that the no-feedback game has multiple equilibria. For brevity, we do not develop a particular equilibrium here. Instead, we establish some results on the strategy of the speculator in any equilibrium of the no-feedback game. Then, in the next section, we demonstrate how this strategy changes in the presence of feedback. The following lemma characterizes the strategy of the positively informed speculator and the negatively informed speculator in any equilibrium of the no-feedback game. Building on this lemma, the next proposition establishes an important result regarding the strategy of the speculator when he is uninformed, which is the focus of our paper. Note that we allow for mixed-strategy equilibria. In fact, for many parameter values our model does not have a pure strategy equilibrium.

Lemma 1. In any equilibrium of the no-feedback game the trading strategy of the positively informed speculator is as follows: In $t=1$, he buys with probability $1-\mu^{h}$ and does not trade with probability $\mu^{h}$, where $0 \leq \mu^{h}<1$. In $t=2$, he buys with probability 1 if $p_{1}<V^{+}$and mixes between buying, selling, and not trading if $p_{1}=V^{+}$.

The trading strategy of the negatively informed speculator is as follows: In $t=1$, he sells with probability $1-\mu^{l}$ and does not trade with probability $\mu^{l}$, where $0 \leq \mu^{l}<1$. In $t=2$, he sells with probability 1 if $p_{1}>0$ and mixes between buying, selling, and not trading if $p_{1}=0$.

The trading strategies are rather intuitive. The speculator trades to make a profit on his information and thus buys when he has positive information and sells when he has negative information, with the following two exceptions. First, in $t=2$, he is indifferent between his possible actions if his information was revealed to the market maker after $t=1$ trading. In this case,

8. Alternatively, we could set up a no-feedback game, in which the firm always invests, regardless of the information generated by the financial market. This might happen if managers received private benefits from the investment. All our qualitative results go through under this alternative specification, although some quantities such as equilibrium prices and profits would change.

(C) 2008 The Review of Economic Studies Limited 
the price is equal to the true value of the firm $\left(V^{+}\right.$or 0 , depending on whether $\omega=h$ or $l$ ), and thus the speculator makes a profit of 0 regardless of whether he buys, sells, or does not trade. Second, the speculator may randomize in the first date between trading and not trading. This is to reduce the impact of his information on the price and thus increase his trading profit in $t=2$. For example, if the positively informed speculator always bought in $t=1$, then $p_{1}(-1)$, and hence $E\left(p_{2} \mid Q_{1}=-1\right)$ would be very low because $Q_{1}=-1$ would never be associated with a positively informed speculator. This can provide the positively informed speculator a strong incentive to deviate to not trading in $t=1$ and then buying at a low expected price in $t=2$. Of course, if he always refrained from trading in $t=1$, then $p_{1}(-1)$ and $E\left(p_{2} \mid Q_{1}=-1\right)$ would not be very low in equilibrium, and so the positively informed speculator could earn more from deviating to buying in $t=1$ and buying again in $t=2$. Thus, in equilibrium, the positively informed speculator may mix between buying and not trading in $t=1$. Note that for some parameter values there is only a pure-strategy equilibrium, in which the speculator always trades in $t=1$ when he is informed, while for other values there is only a mixed-strategy equilibrium.

The key result of the no-feedback game, which will be contrasted with the result of the feedback game in the next section, is provided by the following proposition.

Proposition 1. In any equilibrium of the no-feedback game, the uninformed speculator never trades in $t=1$.

The intuition behind this result is standard in models of financial markets. Trading in $t=1$ without information generates losses because buying (selling) pushes the price up (down), so that the expected price is higher (lower) than the unconditional expected firm value. Importantly, the uninformed speculator may trade in $t=2$ in equilibrium. This happens when at $t=1$ there is a non-zero noise trade. In this case, the speculator, although uninformed about the future liquidation value, has an informational advantage over the market maker, since he knows that he did not trade, and that the $t=1$ order flow was due to noise. The market maker, who does not know that, adjusts the price to reflect a positive probability that the speculator did trade. Then, the uninformed speculator may have an incentive to buy (sell) in $t=2$ if $p_{1}$ moved below (above) the expected firm value. ${ }^{9}$ This motive will also be present (and developed more fully) in the next section that studies a model with feedback. The focus of the next section will be on how the presence of feedback changes the incentives of the uninformed speculator, so that he will not only trade in $t=2$, but also in $t=1$. This will have important implications for the investment decision of the firm.

\section{EQUILIBRIUM IN A MODEL WITH FEEDBACK: MANIPULATION}

Consider now the case where the manager has no private information about the profitability of the investment project. Moreover, assume that the ex-ante NPV of the project is positive:

$$
\bar{V} \equiv \frac{1}{2}\left(V^{+}+V^{-}\right)>0,
$$

so that without further information, the manager will choose to take the investment. When making the investment decision, the manager may now learn from the information revealed in the trading process. In particular, sell orders will indicate that the speculator is likely to have negative information and thus may lead the manager to reject the investment. Thus, there may be

9. Note that an agent, who is never informed about the firm's liquidation value does not have this informational advantage over the market maker and thus cannot make a profit in equilibrium. 
feedback from the financial market to the investment decision. We call the resulting game the "feedback game". ${ }^{10}$ Note that in this game the stock price has to reflect this feedback, and this is what makes solving the trading model much more involved than in the previous section.

The presence of a feedback effect alters the behaviour of the speculator in a fundamental way. We will show that due to the feedback effect the speculator has an incentive to trade in $t=1$ even when he is uninformed. In particular, in the first trading round, he has an incentive to sell in the absence of information with the aim of establishing an initial short position from which he can profit once he has driven down firm value through further short sales in the second round. Given its nature, we refer to this trading strategy as manipulation. In Section 6, we discuss in detail why manipulation through buy orders is not an optimal trading strategy in this setting.

A crucial condition for the uninformed speculator to be able to profit from the manipulative trading strategy is that the manager decides to cancel the investment following sell orders. Otherwise, the trading of the uninformed speculator does not affect real investment and firm value, as was the case in the no-feedback game of the previous section. In equilibrium, this implies that the information content of a sell order is strong enough to justify the cancellation of the investment, even though it is known that the sell order could be generated by both the negatively informed and the uninformed speculator. In particular, the following condition will be used below:

$$
\frac{\alpha}{2} V^{-}+(1-\alpha) \bar{V}<0
$$

This condition implies that the probability $\alpha$ of informed trade is sufficiently high so that the firm optimally rejects the project after orders that do not distinguish between the negatively informed and the uninformed speculator.

The following proposition shows that in the presence of feedback, there exists an equilibrium where the uninformed speculator employs a manipulative strategy and sells in $t=1$. As in the previous section, this is a mixed-strategy equilibrium.

Proposition 2 (Manipulation). In the presence of feedback, if (3) and (4) are satisfied, then there exists an equilibrium in which the uninformed speculator sells with strictly positive probability in $t=1$.

\subsection{Characterization of equilibrium strategies}

We now turn to characterize the strategies in an equilibrium that features manipulation. We start with the speculator's trading strategy and continue with the firm's investment decision.

In $t=1$, the speculator buys if he has positive information. If he has negative information or no information, he either sells or does not trade. We use $\mu$ to denote the probability that he does not trade, conditional on being negatively informed or uninformed, and so $1-\mu$ is the probability that he sells in this case. Note that $\mu$ is the same for the uninformed and the negatively informed speculator. This is a feature of the equilibrium, not a constraint. ${ }^{11}$ Formally,

$$
u_{1}(s=h)=1,
$$

10. In a previous version of the paper, we studied feedback when the manager may have some private information. In that version, the set-up of the trading model was less rich than it is here. The results were very similar.

11. Note that even though the negatively informed and uninformed speculators get different profits, they face an identical trade off between selling and not trading in $t=1$. Thus, for the mixing equilibrium to obtain, one equation has to hold for both types of speculators to be indifferent. This is why we can characterize an equilibrium with one parameter $\mu$ that determines the mixing probabilities for both speculators. Since both speculators use the same mixing probabilities, the condition for this equilibrium to hold is (4). 


$$
u_{1}(s=l \text { or } \varnothing)=\left\{\begin{array}{lll}
-1 & \text { prob } & 1-\mu \\
0 & \text { prob } & \mu
\end{array} .\right.
$$

The probability $\mu$ is determined endogenously in equilibrium. We show in the proof that $0 \leq \mu<\frac{1-\alpha}{3-\alpha}$.

In $t=2$, after $Q_{1}=2$, the information of the positively informed speculator is revealed, and he is then indifferent between buying, selling, and not trading. Thus, he mixes between the three actions with strictly positive probability on each one. ${ }^{12}$ If $Q_{1}=0$ or 1 , the information of the positively informed speculator is not revealed, in which case he buys again in $t=2$. Formally

$$
u_{2}\left(s=h, Q_{1}, u_{1}=1\right)=\left\{\begin{array}{lll}
1 & \text { if } & Q_{1} \in\{0,1\} \\
-1,0, \text { or } 1 & \text { if } & Q_{1}=2 .
\end{array}\right.
$$

As for the negatively informed speculator, if $Q_{1}=-2$ or -1 , it is known that the speculator is either negatively informed or uninformed, so by (4), no investment occurs regardless of $t=2$ order flow and prices are 0 . The speculator is therefore indifferent in $t=2$ between buying, selling, and not trading, so he uses a mixed strategy with strictly positive probability on each action. If $Q_{1}=0$ or 1 , the negatively informed speculator sells again in $t=2$. Formally

$$
\begin{gathered}
u_{2}\left(s=l, Q_{1}, u_{1}=-1\right)=\left\{\begin{array}{lll}
-1 & \text { if } & Q_{1}=0 \\
-1,0, \text { or } 1 & \text { if } & Q_{1} \in\{-1,-2\},
\end{array}\right. \\
u_{2}\left(s=l, Q_{1}, u_{1}=0\right)=\left\{\begin{array}{lll}
-1 & \text { if } & Q_{1} \in\{0,1\} \\
-1,0, \text { or } 1 & \text { if } & Q_{1}=-1 .
\end{array}\right.
\end{gathered}
$$

Finally, the uninformed speculator follows exactly the same strategy as the negatively informed speculator in $t=2$, including all mixing probabilities, with only one exception: If the uninformed speculator does not trade in $t=1$, and $Q_{1}=0$ occurs, he does not trade in $t=2$ (the negatively informed speculator sells at this node). Formally

$$
\begin{gathered}
u_{2}\left(s=\varnothing, Q_{1}, u_{1}=-1\right)=\left\{\begin{array}{lll}
-1 & \text { if } & Q_{1}=0 \\
-1,0, \text { or } 1 & \text { if } & Q_{1} \in\{-1,-2\},
\end{array}\right. \\
u_{2}\left(s=\varnothing, Q_{1}, u_{1}=0\right)=\left\{\begin{array}{lll}
-1 & \text { if } & Q_{1}=1 \\
0 & \text { if } & Q_{1}=0 \\
-1,0, \text { or } 1 & \text { if } & Q_{1}=-1 .
\end{array}\right.
\end{gathered}
$$

In $t=3$, the firm chooses to reject the investment after all nodes that are consistent with the negatively informed and the uninformed speculator and are not consistent with the positively informed speculator. Given the above trading strategies, the firm chooses to reject the investment for any $Q_{2}$ following $Q_{1} \in\{-2,-1\}$. If $Q_{1}=0$ or 1 , the firm rejects the investment when $Q_{2} \in\{-2,-1\}$. In all other cases the firm invests. Equilibrium market prices in $t=2$ are 0 following nodes that generate no investment. They reflect the expected profit from the investment, given the order flows, following all other nodes. Prices in $t=1$ reflect the expected $t=2$ price, given $t=1$ order flow.

12. The probabilities assigned to the different actions are not important, but we restrict attention to an equilibrium in which they are all strictly positive. This implies that all $Q_{2} \in\{-2, \ldots, 2\}$ occur in equilibrium, and our result therefore does not depend on any assumptions about off-the-path beliefs. 


\subsection{The profit from manipulation}

The key feature of the equilibrium described above is that the uninformed speculator sells in $t=1$ with positive probability (i.e. $\mu<1$ ). The following corollary characterizes his strategy more precisely. It follows directly from the proof of Proposition 2.

Corollary 1. In the equilibrium characterized in Section 4.1, when $V^{+}(1-\alpha) \leq \bar{V}$, the uninformed speculator sells in $t=1$ with probability 1 (i.e. $\mu=0$ ). When $V^{+}(1-\alpha)>\bar{V}$, he sells in $t=1$ with a probability that is strictly above $\frac{2}{3-\alpha}$ (i.e. $\mu<\frac{1-\alpha}{3-\alpha}$ ).

We now explore, in more detail, the profit that the uninformed speculator gains from selling in $t=1$.

After selling in $t=1$, the uninformed speculator faces three possible price paths. With probability $\frac{2}{3}$, the fact that the speculator must be either uninformed or negatively informed is revealed to the market maker in the first round $\left(Q_{1}=-2\right.$ or -1$)$. In this case, given (4), the updated NPV of the investment from the point of view of the market maker and the firm's manager is negative. Thus, prices drop to 0 and so does the value of the firm. As a result, along this path, the speculator makes a profit of 0 .

With probability $\frac{2}{9}$, the speculator's identity as uninformed or negatively informed is revealed only in the second round $\left(Q_{1}=0, Q_{2}=-2\right.$ or -1$)$. In this case, one unit of his short position is established at the positive price $p_{1}(0)$ and the other unit is established at a price of 0 . Since the firm does not take the investment after this price path the value of the firm is 0 and the uninformed speculator's profit is $p_{1}(0)$.

Finally, with probability $\frac{1}{9}$, the speculator's identity as uninformed or negatively informed is not revealed in either round of trade $\left(Q_{1}=0, Q_{2}=0\right)$. In this case, the speculator establishes one unit of his short position at a price of $p_{1}(0)$ and another unit at a price of $p_{2}(0,0)$. Given this path, and from (3), the firm invests. Conditional on the speculator's information $(s=\varnothing)$ the expected firm value is thus $\bar{V}$. Note that $p_{2}(0,0)$ is equal to $\bar{V}$ : given $Q_{1}=0$ and $Q_{2}=0$, the trading process reveals no new information regarding the profitability of the project, so the expected value from the point of view of the market maker remains $\bar{V}$. Thus, along this path, the speculator makes a profit of $p_{1}(0)-\bar{V}$. This profit is strictly positive. This is because the price $p_{1}(0)$ reflects the possibility that $t=2$ trading will reveal private information and therefore improve resource allocation (i.e. lead the manager to reject the investment in the low state of the world with positive probability). Thus, $p_{1}(0)$ is greater than the value of the investment absent any information $(\bar{V})$.

After multiplying the profits by the respective probabilities, we get that the expected profit of the uninformed speculator from selling in $t=1$ is $\frac{1}{3}\left(p_{1}(0)-\frac{1}{3} \bar{V}\right)$. This profit can be attributed to two different sources; both generated by the allocational role of prices. First, the speculator can sell in $t=1$ at a price $p_{1}(0)>\bar{V}$. From the perspective of the uninformed speculator, he can profit from selling at this price. This is because the price reflects the possibility that $t=$ 2 prices will have an allocational role and therefore increase firm value. However, given that $s=\varnothing$ the speculator knows that prices will not actually fulfil this role. This effect generates an expected profit of $\frac{1}{3}\left(p_{1}(0)-\bar{V}\right)$ for the speculator. Second, in our model, the speculator starts with no initial position. Thus, his trading strategy entails short selling the stock in $t=1$ and then short selling again in $t=2$. This generates a profit from distorting the firm's investment decision towards rejecting the project when it should accept it. Specifically, by selling in $t=2$, the speculator drives down the price of the stock and decreases the value of the firm. This is because the firm responds to a low stock price by rejecting the investment project, even though the optimal investment policy conditional on the speculator's information $(s=\varnothing)$ would have 
generated $\bar{V}>0$. This increases the value of the short position acquired by the speculator in $t=1$, generating an overall increase of $\frac{2}{9} \bar{V}$ in his expected profit. It is because of this feature that we say that the uninformed speculator manipulates the price when he (short) sells in $t=1$.

To clarify the role of short sales (vs. regular sales), note that short selling is necessary for the second source of profit to arise, whereas the first source would have existed even if the speculator started with an (exogenous) long position and sold some portion of it over the two rounds of trade. Yet, it is not clear whether in such a case the trading strategy would be overall desirable for the uninformed speculator. This is because when selling without information the speculator pushes the firm to take the wrong investment decision. When he has a long position, this adversely affects his overall profit. Thus, short selling is an important, sometimes even necessary, element of the uninformed speculator's trading strategy.

Another important point is that the two sources of profit described above rely crucially on the existence of more than one round of trade. First, in a model with only one round of trade, the price that corresponds to a total order flow of 0 would not be above $\bar{V}$. This is because when there are no additional rounds of trade, a total order flow of 0 implies that the financial market is not going to have an allocational role. Second, in such a model, the speculator cannot make a profit by establishing a short position and then distorting the value of the firm with further short sales. Since there is only one round of trade, any distortion in the value of the firm must be reflected in the price at which the speculator establishes his short position, and this prevents him from making a profit.

After describing the sources of profit for the uninformed speculator from selling in $t=1$, it is useful to remind the reader that if the uninformed speculator does not trade in $t=1$, he still makes a positive expected profit since he may benefit from mispricing caused by the $t=1$ noise trade. Specifically, if $Q_{1}=1$ due to noise trade, the market price overestimates the value of the firm given that the speculator is uninformed, and thus the uninformed speculator can profit from selling in $t=2$. This source of profit also exists when there is no feedback as in Section 3. When there is feedback, the uninformed speculator will either always sell in $t=1$ or mix between the two strategies (when $V^{+}(1-\alpha)>\bar{V}$ ).

\subsection{Manipulation and firm value}

Whether the uninformed speculator sells in $t=1$ or not has significant implications for the ex-ante efficiency of the firm's investment decision and thus for the value of the firm. This is established in the following corollary, which follows directly from the proof of Proposition 2.

Corollary 2. In the equilibrium characterized in Section 4.1, conditional on the speculator being uninformed, the expected value of the firm is $\frac{1}{9} \bar{V}$ if the speculator sells in $t=1$, and $\frac{1}{3} \bar{V}$ if the speculator does not trade in $t=1$. Thus, by selling in $t=1$, the uninformed speculator decreases the expected value of the firm by $\frac{2}{9} \bar{V}$.

The intuition behind this result is simple. When selling in $t=1$, the uninformed speculator acts like a negatively informed speculator. As a result, when the manager of the firm observes the outcome of the trading process, he often downgrades his belief regarding the profitability of the investment and decides not to invest. Given that the speculator is uninformed, and that $\bar{V}>0$, this decision decreases the expected value of the firm. Thus, manipulation has a real cost.

In our model, despite the real cost of manipulation, financial markets never decrease the overall expected value of the firm. The reason is simple: If financial markets decreased the overall expected value of the firm, the manager's best response would be to ignore the information generated by the financial market. This, in turn, would destroy the feedback effect and make 
manipulation unprofitable. ${ }^{13}$ Still, our results suggest that investment efficiency can be improved by regulation that decreases the incentive of uninformed speculators to manipulate the price.

One such regulation is to impose a cost on short sales. In general, such a cost has two opposite effects on the efficiency of investment decisions. First, it might decrease efficiency by decreasing the incentive of the negatively informed speculator to short sell, thus preventing negative information from getting into the price and guiding firms' investments. Second, it may increase efficiency by decreasing the incentive of the uninformed speculator to manipulate the price. A useful observation is that, in our manipulation equilibrium, the negatively informed speculator expects to make a higher profit from short selling than the uninformed speculator. This is because the firm sometimes invests after the speculator short sells, in which case the negatively informed speculator needs to cover a short position at a value of $V^{-}$, while the uninformed speculator needs to cover a short position at an expected value of $\bar{V}$ (see the proof of Proposition 2). Thus, by setting the short selling cost at an intermediate level, regulators may be able to drive the uninformed speculator, but not the negatively informed speculator, out of the market. In this case, investment efficiency will be improved. Note that a complete evaluation of such a policy will need to consider other implications it may have on the equilibrium strategies of speculators. Such an analysis is beyond the scope of our paper.

Finally, another possibility is that the firm itself could try to commit to an investment policy that would reduce the profitability of manipulative trading without removing the allocational benefits that informed trade has. One way of achieving this may be for the firm to invest when the order flow is moderately negative, but to reject the investment when the order flow is highly negative. In such a case, the uninformed speculator would be exposed to losses when he short sells and may refrain from manipulation. The firm may be able to commit to such a policy by designing a compensation contract that rewards the manager when he invests, but that is also linked to performance. The rewards for investment should be chosen such that the manager overinvests when the order flow is moderately negative, but rejects the project after a strongly negative order flow. In deciding on its commitment policy, the firm would have to weigh the gain from undermining manipulation against the loss of making interim inefficient investments.

\subsection{Empirical implications}

In this subsection we point out some empirical predictions coming out of our manipulation equilibrium. First, we discuss predictions regarding the informativeness of order flows and prices. Then, we discuss an implication for the effect of selling pressure on real investments. Finally, we discuss predictions regarding when the manipulation equilibrium is expected to occur.

4.4.1. The informativeness of order flows and prices. An interesting feature of our manipulation equilibrium is the asymmetry between buy orders and sell orders. As a result of this asymmetry, prices are more informative about fundamentals following a positive order flow than following a negative order flow. This is summarized in the following corollary, which follows directly from the proof of Proposition 2.

Corollary 3. Consider the equilibrium characterized in Section 4.1:

In $t=1, \operatorname{Pr}\left(s=h \mid Q_{1}=X\right)>\operatorname{Pr}\left(s=l \mid Q_{1}=-X\right)$, where $X \in\{1,2\}$.

In $t=2$, after $Q_{1} \in\{0,1\}, \operatorname{Pr}\left(s=h \mid Q_{1}, Q_{2}=X\right)>\operatorname{Pr}\left(s=l \mid Q_{1}, Q_{2}=-X\right)$.

13. In a previous version of this paper, we studied an extension with multiple firms that exhibit production complementarities. In such a setting, financial markets can decrease the overall expected value of the firm, as the different managers cannot coordinate to choose the collective best response.

(C) 2008 The Review of Economic Studies Limited 
As we can see from the corollary, in the manipulation equilibrium described above, positive order flows are more strongly correlated with high signals than negative order flows are with low signals (in $t=2$ this happens only when there is uncertainty left after $t=1$ trade). The intuition is simple: since the uninformed speculator pools with the negatively informed one, while the positively informed speculator has a distinct trading strategy, positive information can be more easily inferred from the price than negative information. This result can serve as a basis for empirical testing of our model. Of course, this should be taken with caution, since the fundamentals are not easily observable, and thus empirical tests based on this corollary might be hard (recall that cash flows are not a pure measure of fundamentals, as they are affected by the feedback effect from the price). The following corollary, which addresses the sensitivity of the stock price to order flow, provides a more directly testable hypothesis.

Corollary 4. Consider the equilibrium characterized in Section 4.1:

In $t=1, p_{1}(X)-p_{1}(0)>p_{1}(0)-p_{1}(-X)$, where $X \in\{1,2\}$.

In $t=2, p_{2}(0, X)-p_{2}(0,0)>p_{2}(0,0)-p_{2}(0,-X)$.

This corollary implies that prices react less strongly to sell orders than to buy orders (in $t=2$ this happens only after $t=1$ trade was balanced). There are two reasons for this. First, due to the feedback effect, the firm value is bounded from below: when the order flow is negative, the firm rejects the investment project, and this mitigates the loss in value due to the realization of the low fundamental. Second, the fact that the uninformed speculator engages in manipulation makes the positive order flow more informative about the state of the world and thus increases the reaction of the price to a buy order.

4.4.2. Selling pressure and real investments. Another direct prediction from our manipulation equilibrium is that after strong selling pressure, firms will pass up investment opportunities that would have had positive NPV. The idea that strong selling pressure leads to cancellation of real investment projects is consistent with the empirical finding by Desai, Ramesh, Thiagarajan and Balacran (2002), who show that stocks are more likely to be delisted (for reasons other than a merger or acquisition) if they are more strongly shorted. When delistings occur due to liquidation, this is indicative of a reduction in investment expenditure, consistent with our model. Of course, being able to tell whether the cancelled investments would have had positive NPV is more difficult, since when the investment is cancelled there is no direct indication on whether or not it had a positive NPV. One way to potentially gauge the NPV of the cancelled investment is by looking at the outcomes of uncancelled investments of comparable firms.

4.4.3. When is manipulation expected? The above predictions originate from an equilibrium with manipulation. The existence of such equilibrium depends, of course, on the presence of sufficiently strong feedback from the financial market to the real economy. We can thus sharpen the empirical implications of our model by saying that the above properties are expected only when feedback is strong enough.

In general, feedback is likely to exist when a big investment decision is about to occur. A sufficient condition for feedback to generate a manipulation equilibrium is then given by (4). We can rewrite this condition as

$$
\alpha>2 \frac{\bar{V}}{\bar{V}+\Delta V},
$$

where $\Delta V \equiv V^{+}-\bar{V}=\bar{V}-V^{-}$is a measure of uncertainty over the prospects of the investment. Using this new formulation, we can analyse the effects of $\bar{V}, \Delta V$, and $\alpha$ on whether the sufficient 
condition for the manipulation equilibrium is satisfied. First, condition (12) is more likely to be satisfied when the investment's ex-ante NPV $\bar{V}$ falls. This is because then the investment is less promising and thus more likely to be abandoned after selling pressure. Second, (12) is more likely to be satisfied when there is more uncertainty over the prospects of the investment. In this case, indication from the financial market that the state of the world might be low is more likely to lead to cancellation of the investment.

Third, (12) is more likely to be satisfied when $\alpha$ is higher. This is because a high $\alpha$ implies that the stock market is more informative about the investment project's fundamentals, and this strengthens the feedback effect. Note that $\alpha$ can be thought of as a measure of the amount of information that markets have, which is not otherwise available to decision-makers in the real economy. The IPO literature has discussed types of information that satisfy this criterion (see Rock, 1986). For example, some speculators are likely to have information about a competitor that could have a significant impact on the firm's product. Alternatively, some speculators may know better than the firm the appropriate rate to discount the firm's cash flows. In mergers and acquisitions, market participants can have useful projections on the prospects for future synergies (see Luo, 2005). Subrahmanyam and Titman (1999) suggest that some market participants may have useful information about the potential of a firm's new product. Finally, for financially constrained firms, investment decisions are effectively being made by providers of capital such as banks. In this case the feedback effect is expected to be particularly strong (Baker et al., 2003) because outside providers of capital can learn from the information in the market on many aspects of the firm's life.

\section{THE (IM)POSSIBILITY OF EQUILIBRIUM WITH NO MANIPULATION: THE CASE OF STRONG FEEDBACK}

In the previous section, we characterized an equilibrium with manipulation when the firm's investment decision is contingent on the stock price. An interesting question is whether all equilibria in such a game exhibit manipulation; that is, whether, in a game with feedback, the uninformed speculator always sells with positive probability in $t=1$. We now address this question.

Suppose the speculator were to trade according to the equilibrium strategies characterized in Section 4.1 when he is positively or negatively informed, but would not trade in $t=1$ when he is uninformed. Given this, the uninformed speculator's best response would be to sell in $t=1$. To see this, note that, taking other strategies as given, $p_{1}(0)$ increases if the market maker believes that the uninformed speculator does not sell in $t=1$. This is because, in the absence of manipulation, prices perform a better allocational role, so the expected value of the firm increases. This increases the incentive for the uninformed speculator to sell in $t=1$ (relative to the equilibrium characterized in Section 4.1), and so manipulation must occur. ${ }^{14}$ In equilibrium, however, things become more complicated, because we cannot take as given the strategies of the speculator when he is positively or negatively informed. For example, an increase in $p_{1}(0)$ reduces the incentives for the positively informed speculator to buy in $t=1$, which may lead him to mix between buying and not trading in $t=1$. The firm will then cancel the investment less often, because the positively informed speculator's trade is now closer to that of the negatively informed speculator, and it is therefore more difficult to extract negative information from the price. This reduces the incentive of the uninformed speculator to manipulate, since he ends up holding a short position in a firm that invests and thus has value.

Due to such issues, we cannot generally rule out equilibria without manipulation in a game with feedback. We can, however, rule them out when the feedback effect is sufficiently strong,

14. This effect is strengthened by the fact that, under the belief that the uninformed speculator does not trade in $t=1$, other prices change in a way that his profit from waiting and trading only in $t=2$ decreases.

(C) 2008 The Review of Economic Studies Limited 
that is, when the firm has a strong tendency to cancel the investment when the order flow is negative. From Equation (12) we know that a strong feedback effect can be a result of a small $\bar{V}$, a large $\Delta V$, or a large $\alpha$. In this section, we consider a strong feedback effect that results from a small $\bar{V}>0$. Proposition 3 shows that for a sufficiently small $\bar{V}$, there is no equilibrium where the uninformed speculator does not sell in $t=1$.

Proposition 3. In the presence of feedback, when $\bar{V}>0$ is sufficiently small, the uninformed speculator sells in $t=1$ with positive probability in any equilibrium in which off-the-path beliefs satisfy the intuitive criterion.

This result rounds off our illustration of how feedback opens up the possibility of manipulation. We proved earlier that in the absence of feedback, manipulation by the uninformed speculator never occurs (Proposition 1), while we now showed that it always occurs when the feedback effect is strong (Proposition 3). For an interim case, where feedback may be weaker, we showed that there always exists an equilibrium with manipulation ( Proposition 2), although we could not rule out that other equilibria exist for this case that do not feature manipulation.

The intuition behind this result is simple. As we showed in Section 4.2, the benefit that the uninformed speculator derives from selling in $t=1$ is a result of the feedback from the financial market to the firm's investment decision. The uninformed speculator, however, also faces a potential cost from selling in $t=1$. This results from the fact that he ends up holding a short position in the firm, which may have value if the firm invests. When the feedback effect is sufficiently strong, we can rule out that investment would occur except in a small number of states that can follow two sell orders. This makes it more attractive for the uninformed speculator to sell.

\section{BUYER VS. SELLER INITIATED MANIPULATION}

When the speculator trades in $t=1$ in the absence of information he tends to affect resource allocation. This is important for the profitability of manipulation. In our paper, the uninformed speculator sells the stock, which leads to a decrease in investment. An interesting question is whether the opposite mechanism could generate manipulation initiated through buy orders. We now analyse this possibility.

In principle, it is easy to have a model where the uninformed speculator's action leads to an increase in investment. This requires that $\bar{V}<0$, that is, that no investment occurs in the absence of any information over future productivity. Then, a speculator without information could buy shares, drive up the stock price and get the firm to invest. Such a trading strategy is feasible, but as we show in the following proposition, it can never be profitable.

Proposition 4. If $\bar{V}<0$, there is no equilibrium where the uninformed speculator makes a positive profit from buying in $t=1$.

To gain intuition for this result, it is useful to go back to the two sources of profit behind seller-initiated manipulation, as identified in Section 4.2, and explain why they fail to generate a profit under buyer-initiated manipulation. First, when the uninformed speculator buys in $t=1$, he expects to pay more than the expected value of the firm conditional on the fact that he is uninformed. This is because the price in $t=1$ reflects the possibility that information in the price will increase the value of the firm by improving the efficiency of the investment decision. Paying more than the expected value is, of course, unprofitable. Second, when the uninformed speculator affects the firm's investment decision with his trade, he generates a decrease in firm value, 
regardless of whether his action leads to a decrease or to an increase in the firm's investment. This is because the effect of the financial market on the firm's investment is based on learning. If the manager tries to learn from the financial market when the speculator happens to be uninformed, the manager is essentially misled to thinking that there is information, and thus his investment decision is distorted. As a result, the value of the firm decreases. The speculator can profit from decreasing the value of the firm only when he accumulates a short position, not when he accumulates a long position.

Overall, our model suggests that there is an asymmetry between buyer and seller initiated trades: manipulation of prices via reduction of firms' values can occur only with seller-initiated trades. This also reinforces the regulatory implications explored in Section 4.3: Since buyerinitiated manipulation cannot be optimal, there is some justification for regulators' focus on short sales.

\section{ROBUSTNESS ISSUES}

In this section we analyse the robustness of the manipulation equilibrium characterized in Section 4.1 to two modifications of the model. First, in Section 7.1, we extend the model to include additional strategic traders, who are never informed about the state of the world. Second, in Section 7.2, we endogenize the noise traders' motive for trading by modelling them as risk-averse agents who trade in order to hedge a future risk exposure.

\subsection{Additional uninformed traders}

So far, we assumed that there is only one strategic trader in the financial market. Since this speculator makes a profit from selling even when he fails to get an informative signal, the question arises whether any other uninformed strategic trader could do the same. This might interfere with the equilibrium characterized in Section 4.1 by reducing the expected profits of the original speculator. In this subsection we extend the model to include additional strategic traders (henceforth arbitrageurs) who are never privately informed about the true state. The following proposition shows that the manipulation equilibrium characterized in Section 4.1 is robust to the inclusion of such arbitrageurs in the model.

Proposition 5. When there are additional traders who are never informed, then there exists an equilibrium in which they never trade and the (potentially informed) speculator follows the strategy characterized by (5)-(11).

The intuition behind this result is as follows. An arbitrageur cannot condition his trades on the signal that the speculator has. If an arbitrageur tries to manipulate the price by selling in $t=1$, he therefore ends up selling sometimes when the speculator is positively informed, and therefore he loses money to him by affecting the price in an unfavourable direction. As a result, arbitrageurs make an overall loss from trading and thus prefer not to trade.

\subsection{Endogenous noise trade}

This section extends the analysis of Section 4 to allow for fully rational noise traders. ${ }^{15} \mathrm{We}$ model noise traders as risk-averse agents who trade in order to hedge a future risk exposure that is correlated to the firm's liquidation value. This approach follows Spiegel and Subrahmanyam

15. The additional traders introduced in the previous subsection are not included here. 
(1992) and is adapted to a model with discrete pay-off distributions (see Biais and Hillion, 1994; Dow and Gorton, 1997; and Dow, 1998). ${ }^{16}$

Assume that the value of the firm now consists of the value of assets in place $A$ and the value derived from the additional investment $V(\omega, k)$. The value of the firm in $t=3$ is thus $V(\omega, k)+A$. The value of assets in place $A$ is uncertain and is realized in $t=3$. It can take one of two values $A^{+}$and $A^{-}$, with equal probabilities; $A^{+}>0>A^{-}$. Prior to $t=3$ there is no private information available about the realization of $A$. The stock price therefore increases by the constant $E[A]$ compared to the case previously analysed where $A \equiv 0$. This has no impact on the behaviour of the speculator and the market maker (who are both risk neutral). To ease the exposition, we assume that $E[A]=0$, that is, that $A^{-}=-A^{+}$, so that prices are exactly the same as in Section 4.

There are two noise traders, one who is born just before $t=1$ and one who is born just before $t=2$. Noise traders experience a shock to their $t=3$ endowment, which is correlated to the realization of $A$. The correlation itself is a random variable and may be perfectly positive, perfectly negative, or 0 , with equal probabilities. We can thus denote the uncertain $t=3$ endowment of a noise trader by $e_{g}=z_{g} A$, where $g=1,2$ denotes whether the noise trader is in the early generation $(g=1)$ or in the late generation $(g=2)$, and $z_{g}=-1,0$, or 1 , with equal probabilities. The correlation coefficient $z_{g}$ is independent across the two noise traders. The noise trader of the early generation (late generation) learns the realization of $z_{1}\left(z_{2}\right)$ just before $t=1$ $(t=2)$ and can submit an order to the market maker so as to hedge his future endowment risk. We assume that each noise trader only has access to the market in the same date in which he learns his endowment shock; that is, the $g=1$ noise trader has to trade in $t=1$ if he wishes to trade at all. ${ }^{17}$

The noise trader of generation $g$ submits an order $n_{t=g} \in\{-1,0,1\}$ so as to maximize the expected utility from his final wealth, which is given by

$$
w_{g}=n_{t=g}\left(A+V(\omega, k)-p_{t=g}\right)+z_{g} A .
$$

We assume the following utility function for both noise traders:

$$
U\left(w_{g}\right)=\min \left\{\rho^{-} w_{g}, \rho^{+} w_{g}\right\},
$$

where $\rho^{-}>\rho^{+} \geq 0$. Hence, the utility function is kinked in 0 where its slope flattens from $\rho^{-}$ to $\rho^{+}$. We can therefore use $\Delta \rho \equiv \rho^{-}-\rho^{+} \geq 0$ as a measure of risk aversion.

The following proposition says that for a sufficiently large risk exposure, the noise traders always optimally choose to submit $n_{t=g}=-z_{g}$, and thus the analysis of other agents' equilibrium behaviour remains the same as in Section 4.

Proposition 6. There exists an $A^{*}$, such that for any $A^{+} \geq A^{*}$, noise traders submit orders $n_{t=g}=-z_{g}$, and thus there is an equilibrium where the speculator trades according to equations (5)-(11).

Intuitively, noise traders participate in the market in order to hedge their exposure to $A$. This is costly, because, on average, they lose money to the speculator. For example, when they buy, they are likely to have to trade at a high price, even though their order is unrelated to the

16. The cited papers provide static trading models without feedback. We need to extend the analysis to dynamic trading in the presence of feedback (see also Guembel, 2005, for such a treatment).

17. This assumption is made in order to avoid that hedgers bunch together at the second trading date (see Foster and Viswanathan, 1990). Understanding the dynamics of liquidity trade is an important open research question. Addressing it is beyond the scope of this paper. 
fundamental value of the security. Noise traders therefore are willing to trade if the reduction in risk exposure is worth more than the expected trading loss. If this is the case, their order flows are essentially the same as in the previous sections, and thus the previous results extend to equilibria in which noise trade is endogenized.

To clarify our modelling choices in this subsection, we should emphasize that the purpose of the analysis here is to show that the equilibrium derived under exogenous noise trade is robust to the introduction of endogenous noise traders. Thus, we chose the simplest framework to demonstrate this point. One feature of this framework is that noise traders have exposure to the random variable $A$, which is uncorrelated to the variable about which there is privately informed trade $V$. As was noted in the literature before (see Dow and Rahi, 2003), whether a hedger's exposure is correlated to the variable about which there is privately informed trade has crucial implications for the equilibrium trading behaviour. One effect that could complicate the analysis if noise traders had exposure to $V$ is the Hirshleifer effect, according to which informed trade leads to revelation of information in the price and destroys hedging opportunities. This issue becomes even more complicated with multiple rounds of trade (like in our paper), since it implies that the amount of trade for the purpose of hedging might change from one period to another as more information gets revealed in the price. Thus, to avoid these issues, which are not the focus of our paper, we assumed that noise traders have exposure to $A$, which is uncorrelated to $V$. An analysis of the effect of manipulation on liquidity in the presence of exposure to both $A$ and $V$ is an interesting direction for future research.

\section{CONCLUSIONS}

It is commonly believed that financial markets provide information that guides real investment decisions. Yet, most of the theoretical analysis on the informational content of prices in financial markets assumes that the value of traded firms is exogenous and thus that real investments are not affected by the information contained in prices (e.g. Kyle, 1985). In this paper we explicitly incorporate the feedback effect from the financial market to the real economy in a trading model à la Kyle (1985). We show that the presence of a feedback effect changes the scope for speculation in a fundamental way.

Specifically, we study the behaviour of a speculator who may or may not be informed about the state of the world. In a model without feedback, this speculator would buy the stock when he is positively informed, sell the stock when he is negatively informed, and not trade when he is uninformed. Once feedback is introduced, the speculator may have an incentive to sell even when he is uninformed. Selling is profitable for two reasons. First, knowing that he is uninformed, the speculator knows that the stock market will not have a beneficial allocational role. Since this is not known to other market participants, he can sell the stock at a price that is higher than the true expected value. Second, the speculator can profit from the effect of his trade on the firm's investment decision. Specifically, he can establish a short position in the stock and then drive the price down with further sell orders. The decrease in the price will lead to cancellation of real investment projects and to a reduction in the real value of the firm. This will enable the speculator to profit on his short position. We refer to this trading strategy as manipulation.

The importance of identifying the manipulation strategy goes beyond the contribution to the understanding of trading dynamics in financial markets. Due to the feedback effect from the financial market to the real economy, the value of firms decreases when speculators engage in manipulation. Thus, manipulation reflects a limitation that is inherent in the beneficial allocational role of prices. Yet, despite this feature, financial markets still improve the overall efficiency of investment decisions. After all, if this was not the case, then prices would lose their allocational role, and the possibility to manipulate them would disappear. An implication of our paper is that 
regulation aimed at stifling incentives for manipulation can increase real efficiency further. An example for such regulation is to impose restrictions on short sales. Our analysis also generates novel empirical implications on the relation between order flows, prices, and real investments.

\section{APPENDIX}

Proof of Lemma 1. We start by analysing the strategy of the positively informed speculator in $t=2$. When choosing his $t=2$ trade, the speculator acts to maximize the profit on his $t=2$ transaction (this is given by $V^{+}-E\left[p_{2} \mid Q_{1}, u_{2}=1\right]$ if he buys; 0 if he does not trade; and $E\left[p_{2} \mid Q_{1}, u_{2}=-1\right]-V^{+}$if he sells). We can distinguish between two cases. First, if his order in $t=1$ revealed his information to the market maker, the price in $t=2, p_{2}$, is always equal to the true value $V^{+}$, and thus the speculator is indifferent between buying, selling, and not trading. Second, if he was not revealed in $t=1$, he makes a positive expected profit by buying in $t=2$. This is because there is a positive probability that he will not be revealed (a total order flow of 0 is never revealing and it happens with probability $\frac{1}{3}$ ) in which case he will pay a price lower than the true value $V^{+}$and thus make a positive profit. (If he is revealed, his profit is 0 .) On the other hand, his profit is 0 if he does not trade, and no more than 0 if he sells: The value of the firm is $V^{+}$while the price cannot exceed that. Hence, he buys. Similarly, the negatively informed speculator is indifferent between the three possible actions in $t=2$ if his identity was revealed in $t=1$. He sells after not being revealed in $t=1$.

Now, let us go back to $t=1$. By the law of iterated expectations, the price in $t=1$ can be written as

$$
\begin{aligned}
p_{1}\left(Q_{1}\right)= & \operatorname{Pr}\left[s=h \mid Q_{1}\right] \cdot E\left[p_{2} \mid u_{2}\left(s=h, Q_{1}, u_{1}\right), Q_{1}\right] \\
& +\operatorname{Pr}\left[s=\varnothing \mid Q_{1}\right] \cdot E\left[p_{2} \mid u_{2}\left(s=\varnothing, Q_{1}, u_{1}\right), Q_{1}\right] \\
& +\operatorname{Pr}\left[s=l \mid Q_{1}\right] \cdot E\left[p_{2} \mid u_{2}\left(s=l, Q_{1}, u_{1}\right), Q_{1}\right] .
\end{aligned}
$$

If $Q_{1}$ is fully revealing of the speculator's type, that is, if either $\operatorname{Pr}\left[s=h \mid Q_{1}\right]=1, \operatorname{Pr}\left[s=\varnothing \mid Q_{1}\right]=1$, or $\operatorname{Pr}\left[s=l \mid Q_{1}\right]=1$, then $p_{2}$ is always equal to $p_{1}$ and reflects the expected value of the asset given the information of the speculator. In such a case, the speculator makes no profit on his overall trade. If $Q_{1}$ is not fully revealing, then we know that the positively informed speculator always buys, and the negatively informed speculator always sells in $t=2$. As a result, buying in $t=2$ pushes the expected price weakly above $p_{1}: E\left[p_{2} \mid u_{2}=1, Q_{1}\right] \geq p_{1}\left(Q_{1}\right)$. The inequality becomes strict when $\operatorname{Pr}\left[s=l \mid Q_{1}\right]>0$. Similarly, selling in $t=2$ pushes the expected price weakly below $p_{1}$ : $E\left[p_{2} \mid u_{2}=-1, Q_{1}\right] \leq p_{1}\left(Q_{1}\right)$. The inequality becomes strict when $\operatorname{Pr}\left[s=h \mid Q_{1}\right]>0$.

Using these observations, we first rule out the possibility that the positively informed speculator sells in $t=1$. Suppose that the positively informed trader does sell in $t=1$. If he is revealed, his total profit (i.e. the sum of profits on $t=1$ trade and $t=2$ trade) is 0 . If he is not revealed, he will buy in $t=2$. This yields a total profit of $p_{1}\left(Q_{1}\right)-E\left[p_{2} \mid\right.$ $\left.u_{2}=1, Q_{1}\right]$. We know that this cannot be positive. Moreover, it will be strictly negative when $\operatorname{Pr}\left[s=l \mid Q_{1}\right]>0$. Now, when $Q_{1}=0$, which happens with probability $\frac{1}{3}, \operatorname{Pr}\left[s=l \mid Q_{1}\right]$ must be positive. As a result, the positively informed speculator expects a strictly negative total profit from selling in $t=1$. Hence, he will not sell. Similarly, the negatively informed speculator will not buy in $t=1$.

Now let us use $\mu^{h}\left(\mu^{l}\right)$ to denote the probability that the positively informed (negatively informed) speculator does not trade in $t=1$ in equilibrium. Also, let us use $\mu^{\varnothing,-1}\left(\mu^{\varnothing, 1}\right)$ to denote the probability that the uninformed speculator sells (buys) in $t=1$ in equilibrium. We can then express $p_{1}(1), p_{1}(0)$, and $p_{1}(-1)$ as follows:

$$
\begin{aligned}
p_{1}(1) & =\frac{\left(\alpha+(1-\alpha)\left(1-\mu^{\varnothing,-1}\right)\right) V^{+}}{2(1-\alpha)\left(1-\mu^{\varnothing,-1}\right)+\alpha\left(1+\mu^{l}\right)}, \\
p_{1}(0) & =\frac{V^{+}}{2}, \\
p_{1}(-1) & =\frac{\left(\alpha \mu^{h}+(1-\alpha)\left(1-\mu^{\varnothing, 1}\right)\right) V^{+}}{2(1-\alpha)\left(1-\mu^{\varnothing, 1}\right)+\alpha\left(1+\mu^{h}\right)} .
\end{aligned}
$$

Given these prices, we can show that the positively informed speculator buys in $t=1$ with positive probability, that is, that $\mu^{h}<1$. By way of contradiction suppose $\mu^{h}=1$. Then, the positively informed speculator's total expected profits are

$$
\begin{gathered}
V^{+}-\frac{1}{3} E\left[p_{2} \mid u_{2}=1, Q_{1}=1\right] \\
-\frac{1}{3} E\left[p_{2} \mid u_{2}=1, Q_{1}=0\right] \\
-\frac{1}{3} E\left[p_{2} \mid u_{2}=1, Q_{1}=-1\right] .
\end{gathered}
$$

(C) 2008 The Review of Economic Studies Limited 
If he deviates and buys in $t=1$, his total expected profits are at least

$$
\begin{aligned}
& \frac{1}{3}\left(2 V^{+}-p_{1}(1)-E\left[p_{2} \mid u_{2}=1, Q_{1}=1\right]\right) \\
& \quad+\frac{1}{3}\left(2 V^{+}-p_{1}(0)-E\left[p_{2} \mid u_{2}=1, Q_{1}=0\right]\right) .
\end{aligned}
$$

Thus, the expected gain from deviating is at least

$$
\frac{1}{3} V^{+}-\frac{1}{3} p_{1}(1)-\frac{1}{3} p_{1}(0)+\frac{1}{3} E\left[p_{2} \mid u_{2}=1, Q_{1}=-1\right]
$$

The positively informed speculator will deviate when this is positive. Since $\operatorname{Pr}\left[s=l \mid Q_{1}=-1\right]>0$, we know that $\frac{1}{3} E\left[p_{2} \mid u_{2}=1, Q_{1}=-1\right]>p_{1}(-1)$. Thus, it suffices to show that

$$
V^{+}-p_{1}(1)-p_{1}(0)+p_{1}(-1) \geq 0 \text {. }
$$

This is always true since $V^{+} \geq p_{1}(1)$ and when $\mu^{h}=1$, then $p_{1}(0)=p_{1}(-1)$. Thus, the positively informed speculator buys in $t=1$ with positive probability. Similarly, we can show that the negatively informed speculator sells with positive probability.

Proof of Proposition 1. We show that for the uninformed speculator, trading in $t=1$ generates a strictly negative total profit. Suppose that the uninformed speculator buys in $t=1$. The total order flow in $t=1 \mathrm{can}$ be 0,1 , or 2 . Because $\mu^{h}$ and $\mu^{l}$ are strictly below 1 , we know that $p_{1}(1)>\frac{V^{+}}{2}$ and $p_{1}(2)>\frac{V^{+}}{2}$. We also know that $p_{1}(0)=\frac{V^{+}}{2}$. Thus, since the uninformed speculator expects the value of the firm to be $\frac{V^{+}}{2}$, buying in $t=1$ generates a strictly negative profit on his $t=1$ transaction. Then, if he does not trade in $t=2$, his total profit remains negative. If he buys again in $t=2$, the expected price only increases, and thus his total profit remains negative. If he sells in $t=2$, his total profit is $E\left[p_{2} \mid u_{2}=-1, Q_{1}\right]-p_{1}\left(Q_{1}\right)$. We know that this cannot be positive. Moreover, given that the positively informed speculator is expected to buy in $t=2$, selling in $t=2$ pushes the expected price strictly below $p_{1}$, so the expected profit is negative. As a result, in equilibrium, the uninformed speculator never buys in $t=1$. Similarly, we can show that he never sells in $t=1$.

Proof of Proposition 2. The trading strategies in our proposed manipulation equilibrium are given by equations (5)-(11). Our proof that this is an equilibrium has three parts. In Part A, we determine market prices and the firm's investment strategy given the equilibrium trading strategies. In Part $\mathrm{B}$, we show that $t=2$ trading strategies are optimal given market prices and the firm's investment decision. In Part $\mathrm{C}$, we show that $t=1$ trading strategies are optimal given market prices, the firm's investment decision, and taking into account the future $t=2$ strategies.

\section{A. Market prices and the firm's investment}

The investment policy of the firm is to invest when the expected value of investment is positive and not to invest when it is negative. The expected value is calculated based on prior information and on observed order flows. Given the equilibrium strategies and assumptions (3) and (4), the firm does not invest when $Q_{1} \in\{-1,-2\}$, or when $Q_{1} \in\{1,0\}$ and $Q_{2} \in$ $\{-1,-2\}$. Otherwise, the firm invests. The price in $t=2$ is 0 when the firm is not going to invest, and reflects the expected value of the investment otherwise. Thus, using Bayesian updating, $t=2$ prices are

$$
\begin{aligned}
p_{2}\left(Q_{1}, Q_{2}\right) & =0, \quad \text { when } Q_{1} \in\{-2,-1\}, \text { or } Q_{1} \in\{0,1\} \text { and } Q_{2} \in\{-2,-1\}, \\
p_{2}\left(Q_{1}, Q_{2}\right) & =V^{+}, \quad \text { when } Q_{1}=2 \text {, or } Q_{1}=1 \text { and } Q_{2} \in\{1,2\} \text {, or } Q_{1}=0 \text { and } Q_{2}=2, \\
p_{2}(0,0) & =\bar{V}, \quad p_{2}(0,1)=\frac{\alpha V^{+}+2(1-\alpha) \mu \bar{V}}{\alpha+2(1-\alpha) \mu}, \quad p_{2}(1,0)=\frac{\alpha V^{+}+2(1-\alpha) \mu \bar{V}+\alpha \mu V^{-}}{\alpha(1+\mu)+2(1-\alpha) \mu} .
\end{aligned}
$$

$t=1$ prices are then given by the expected $t=2$ prices:

$$
\begin{aligned}
& p_{1}(2)=V^{+} \\
& p_{1}(1)=\frac{1}{3} p_{2}(1,0)+\frac{2}{3} \frac{\alpha V^{+}}{\alpha(1+\mu)+2(1-\alpha) \mu}, \\
& p_{1}(0)=\frac{1}{3} \bar{V}+\frac{1}{3}\left[\frac{\alpha}{2}+(1-\alpha) \mu\right] p_{2}(0,1)+\frac{1}{3} \frac{\alpha}{2} V^{+}, \\
& p_{1}(-1)=0 \\
& p_{1}(-2)=0 .
\end{aligned}
$$




\section{B. Trading strategies in $t=2$}

We show that the trading strategies in $t=2$ are optimal at every possible node on the equilibrium path.

Positively informed speculator who buys in $t=1$ : If $Q_{1}=2$, all actions generate a total profit of 0 , so he is indifferent. If $Q_{1}=1$, buying generates a total profit of $2 V^{+}{ }_{-} p_{1}(1)-\frac{2}{3} V^{+}-\frac{1}{3} p_{2}(1,0)$, not trading generates $\frac{2}{3} V^{+}-$ $p_{1}(1)$, and selling generates $\frac{1}{3} p_{2}(1,0)-p_{1}(1)$, so he chooses to buy. If $Q_{1}=0$, buying generates $2 V^{+}-p_{1}(0)-$ $\frac{1}{3} V^{+}-\frac{1}{3} p_{2}(0,1)-\frac{1}{3} \bar{V}$, not trading generates $\frac{2}{3} V^{+}-p_{1}(0)$, and selling generates $\frac{1}{3} \bar{V}-p_{1}(0)$, so he chooses to buy.

Uninformed speculator who sells in $t=1$ : If $Q_{1}=0$, buying generates $p_{1}(0)-\frac{1}{3} V^{+}-\frac{1}{3} p_{2}(0,1)-\frac{1}{3} \bar{V}$, not trading generates $p_{1}(0)-\frac{2}{3} \bar{V}$, and selling generates $p_{1}(0)+\frac{1}{3} \bar{V}-\frac{2}{3} \bar{V}$, so he chooses to sell. If $Q_{1}=-1$, all actions generate a total profit of 0 , so he is indifferent. If $Q_{1}=-2$, all actions generate a total profit of 0 , so he is indifferent.

Uninformed speculator who does not trade in $t=1$ : If $Q_{1}=1$, buying generates $\bar{V}-\frac{2}{3} V^{+}-\frac{1}{3} p_{2}(1,0)$, not trading generates 0 , and selling generates $\frac{1}{3} p_{2}(1,0)-\frac{1}{3} \bar{V}$, so he chooses to sell. If $Q_{1}=0$, buying generates $\bar{V}-\frac{1}{3} \bar{V}-$ $\frac{1}{3} p_{2}(0,1)-\frac{1}{3} V^{+}$, not trading generates 0 , and selling generates 0 , so he is indifferent between not trading and selling. In our equilibrium, he chooses not to trade. If $Q_{1}=-1$, all actions generate total profit of 0 , so he is indifferent.

Negatively informed speculator who sells in $t=1$ : If $Q_{1}=0$, buying generates $p_{1}(0)-\frac{1}{3} V^{+}-\frac{1}{3} p_{2}(0,1)-$ $\frac{1}{3} \bar{V}$, not trading generates $p_{1}(0)-\frac{2}{3} V^{-}$, and selling generates $p_{1}(0)+\frac{1}{3} \bar{V}-\frac{2}{3} V^{-}$, so he chooses to sell. If $Q_{1}=-1$, all actions generate a total profit of 0 , so he is indifferent. If $Q_{1}=-2$, all actions generate a total profit of 0 , so he is indifferent.

Negatively informed speculator who does not trade in $t=1$ : If $Q_{1}=1$, buying generates $V^{-}-\frac{2}{3} V^{+}-\frac{1}{3} p_{2}(1,0)$, not trading generates 0 , and selling generates $\frac{1}{3} p_{2}(1,0)-\frac{1}{3} V^{-}$, so he chooses to sell. If $Q_{1}=0$, buying generates $V^{-}-\frac{1}{3} \bar{V}-\frac{1}{3} p_{2}(0,1)-\frac{1}{3} V^{+}$, not trading generates 0 , and selling generates $\frac{1}{3} \bar{V}-\frac{1}{3} V^{-}$, so he chooses to sell. If $Q_{1}=-1$, all actions generate total profit of 0 , so he is indifferent.

\section{Trading strategies in $t=1$}

In the proposed equilibrium, the uninformed speculator makes a total expected profit of $\frac{1}{3}\left(p_{1}(0)-\frac{1}{3} \bar{V}\right)$ if he sells in $t=1$, and $\frac{1}{3}\left(\frac{1}{3} p_{2}(1,0)-\frac{1}{3} \bar{V}\right)$ if he does not trade. The negatively informed speculator makes a total expected profit of $\frac{1}{3}\left(p_{1}(0)+\frac{1}{3} \bar{V}-\frac{2}{3} V^{-}\right)$if he sells in $t=1$, and $\frac{1}{3}\left(\frac{1}{3} p_{2}(1,0)+\frac{1}{3} \bar{V}-\frac{2}{3} V^{-}\right)$if he does not trade. Thus, both of them will sell in $t=1$ when $p_{1}(0)>\frac{1}{3} p_{2}(1,0)$, not trade in $t=1$ when $p_{1}(0)<\frac{1}{3} p_{2}(1,0)$, and mix between the two when $p_{1}(0)=\frac{1}{3} p_{2}(1,0)$. Of course, $p_{1}(0)$ and $\frac{1}{3} p_{2}(1,0)$ are affected by $\mu$. We can show that $p_{1}(0)$ is increasing in $\mu$, while $\frac{1}{3} p_{2}(1,0)$ is decreasing in $\mu$. Moreover, when $\mu=\frac{1-\alpha}{3-\alpha}, p_{1}(0)>\frac{1}{3} p_{2}(1,0)$, while when $\mu=0, p_{1}(0)>\frac{1}{3} p_{2}(1,0)$ if and only if $V^{+}(1-\alpha) \leq \bar{V}$. Thus, the equilibrium result is the following: When $V^{+}(1-\alpha) \leq \bar{V}$, then $\mu=0$. When $V^{+}(1-\alpha)>\bar{V}$, then $0<\mu<\frac{1-\alpha}{3-\alpha}$, and $\mu$ is uniquely determined by $p_{1}(0)=\frac{1}{3} p_{2}(1,0)$.

Overall, equilibrium profits for the uninformed speculator are thus $\frac{1}{3}\left(p_{1}(0)-\frac{1}{3} \bar{V}\right)$; equilibrium profits for the negatively informed are $\frac{1}{3}\left(p_{1}(0)+\frac{1}{3} \bar{V}-\frac{2}{3} V^{-}\right)$; while equilibrium profits for the positively informed are: $V^{+}-\frac{1}{3} p_{1}(1)-$ $\frac{1}{3} p_{1}(0)-\frac{1}{9} p_{2}(0,1)-\frac{1}{9} p_{2}(1,0)-\frac{1}{9} \frac{3}{V}$. By assumptions (3) and (4), these profits are all strictly positive. We now show that deviations from the $t=1$ trading strategies generate strictly smaller profits.

Suppose the uninformed speculator buys in $t=1$ : If $Q_{1}=2$ and he buys again in $t=2$, his total profit is $-2 V^{+}+$ $2 \bar{V}$; if he does not trade in $t=2$, his total profit is $-V^{+}+\bar{V}$; while if he sells in $t=2$, his total profit is 0 . If $Q_{1}=1$ and he buys again in $t=2$, his total profit is $-p_{1}(1)-\frac{2}{3} V^{+}-\frac{1}{3} p_{2}(1,0)+2 \bar{V}$; if he does not trade in $t=2$, his total profit is $-p_{1}(1)+\frac{2}{3} \bar{V}$; while if he sells in $t=2$, his total profit is $-p_{1}(1)+\frac{1}{3} p_{2}(1,0)$. Finally, if $Q_{1}=0$ and he buys again in $t=2$, his total profit is $-p_{1}(0)-\frac{1}{3} V^{+}-\frac{1}{3} p_{2}(0,1)+\frac{5}{3} \bar{V}$; if he does not trade in $t=2$, his total profit is $-p_{1}(0)+\frac{2}{3} \bar{V}$; while if he sells in $t=2$, his total profit is $-p_{1}(0)+\frac{1}{3} \bar{V}$. All these profits are either strictly negative or 0 , so the speculator has no incentive to deviate to buying in $t=1$.

Suppose the negatively informed speculator buys in $t=1$ : If $Q_{1}=2$ and he buys again in $t=2$, his total profit is $-2 V^{+}+2 V^{-}$; if he does not trade in $t=2$, his total profit is $-V^{+}+V^{-}$; while if he sells in $t=2$, his total profit is 0 . If $Q_{1}=1$ and he buys again in $t=2$, his total profit is $-p_{1}(1)-\frac{2}{3} V^{+}-\frac{1}{3} p_{2}(1,0)+2 V^{-}$; if he does not trade in $t=2$, his total profit is $-p_{1}(1)+\frac{2}{3} V^{-}$; while if he sells in $t=2$, his total profit is $-p_{1}(1)+\frac{1}{3} p_{2}(1,0)$. Finally, if $Q_{1}=0$ and he buys again in $t=2$, his total profit is $-p_{1}(0)-\frac{1}{3} \bar{V}-\frac{1}{3} V^{+}-\frac{1}{3} p_{2}(0,1)+2 V^{-}$; if he does not trade in $t=2$, his total profit is $-p_{1}(0)+\frac{2}{3} V^{-}$; while if he sells in $t=2$, his total profit is $-p_{1}(0)+\frac{1}{3} \bar{V}$. Again, all these profits are either strictly negative or 0 , so the speculator has no incentive to deviate to buying in $t=1$.

Suppose the positively informed speculator does not trade in $t=1$ : If $Q_{1}=1$ and he buys in $t=2$, his total profit is $\frac{1}{3} V^{+}-\frac{1}{3} p_{2}(1,0)$; if he does not trade in $t=2$, his total profit is 0 ; while if he sells in $t=2$, his total profit is $\frac{1}{3} p_{2}(1,0)-\frac{1}{3} V^{+}$. Thus, he will choose to buy in $t=2$, and make a profit of $\frac{1}{3} V^{+}-\frac{1}{3} p_{2}(1,0)$. If $Q_{1}=0$ and he buys in $t=2$, his total profit is $\frac{2}{3} V^{+}-\frac{1}{3} p_{2}(0,1)-\frac{1}{3} \bar{V}$; if he does not trade in $t=2$, his total profit is 0 ; while if he sells in $t=2$, his total profit is $\frac{1}{3} \bar{V}-\frac{1}{3} V^{+}$. Thus, he will choose to buy in $t=2$, and make a profit of $\frac{2}{3} V^{+}-\frac{1}{3} p_{2}(0,1)-\frac{1}{3} \bar{V}$. 
If $Q_{1}=-1$, all profits are 0 . Overall, the expected profit of the speculator from not trading in $t=1$ is: $\frac{1}{3} V^{+}-\frac{1}{9} p_{2}(1,0)-$ $\frac{1}{9} p_{2}(0,1)-\frac{1}{9} \bar{V}$. This is smaller than his equilibrium profit of $V^{+}-\frac{1}{3} p_{1}(1)-\frac{1}{3} p_{1}(0)-\frac{1}{9} p_{2}(0,1)-\frac{1}{9} p_{2}(1,0)-\frac{1}{9} \bar{V}$, so he will not deviate to not trading in $t=1$.

Suppose the positively informed speculator sells in $t=1$ : If $Q_{1}=0$ and he buys in $t=2$, his total profit is $p_{1}(0)-$ $\frac{1}{3} V^{+}-\frac{1}{3} p_{2}(0,1)-\frac{1}{3} \bar{V}$; if he does not trade in $t=2$, his total profit is $p_{1}(0)-\frac{2}{3} V^{+}$; while if he sells in $t=2$, his total profit is $p_{1}(0)+\frac{1}{3} \bar{V}-\frac{2}{3} V^{+}$. Depending on the parameters, he will either choose to buy or to sell in $t=2$. If $Q_{1}=-1$ or -2 all profits are 0 . Overall, the expected profit of the speculator from selling in $t=1$ is either $\frac{1}{3} p_{1}(0)-\frac{1}{9} V^{+}-$ $\frac{1}{9} p_{2}(0,1)-\frac{1}{9} \bar{V}$, or $\frac{1}{3} p_{1}(0)+\frac{1}{9} \bar{V}-\frac{2}{9} V^{+}$. We can see that $\frac{1}{3} p_{1}(0)-\frac{1}{9} V^{+}-\frac{1}{9} p_{2}(0,1)-\frac{1}{9} \bar{V}$ is smaller than 0 . Thus, to show that the speculator will not deviate to selling in $t=1$ it suffices to show that $\frac{1}{3} p_{1}(0)+\frac{1}{9} \bar{V}-\frac{2}{9} V^{+}$is smaller than his equilibrium profit of $V^{+}-\frac{1}{3} p_{1}(1)-\frac{1}{3} p_{1}(0)-\frac{1}{9} p_{2}(0,1)-\frac{1}{9} p_{2}(1,0)-\frac{1}{9} \bar{V}$. This implies

$$
\frac{11}{9} V^{+}-\frac{1}{3} p_{1}(1)-\frac{2}{3} p_{1}(0)-\frac{1}{9} p_{2}(0,1)-\frac{1}{9} p_{2}(1,0)-\frac{2}{9} \bar{V}>0 \text {. }
$$

Since $p_{1}(0)<\frac{1}{3} V^{+}+\frac{2}{3} \bar{V}$, it suffices to show that:

$$
V^{+}-\frac{1}{3} p_{1}(1)-\frac{1}{9} p_{2}(0,1)-\frac{1}{9} p_{2}(1,0)-\frac{2}{3} \bar{V}>0
$$

This always holds since $V^{+}>2 \bar{V}$. Thus the speculator will not deviate to selling in $t=1$.

Proof of Proposition 3. The Proof has three parts. In Part A, we provide some definitions and preliminary results that become useful later in the proof. In Part B, we consider candidate equilibria where the uninformed speculator does not sell in $t=1$. We show that given any such equilibrium, when $\bar{V}$ is sufficiently small, he strictly prefers to sell in $t=1$ than not to trade. In Part $\mathrm{C}$, we show that in such an equilibrium, when $\bar{V}$ is sufficiently small, he strictly prefers not to trade in $t=1$ than to buy. This implies that the uninformed speculator has a strict incentive to deviate from such a candidate equilibrium by selling in $t=1$. It thus completes the proof that when $\bar{V}$ is sufficiently small, there is no equilibrium where the uninformed speculator does not sell in $t=1$.

\section{A. Preliminaries}

We use $E\left[\pi \mid s, u_{1}\right]$ to denote the expected profit for a speculator with signal $s$ from trading $u_{1}$ in $t=1$, and then choosing the optimal action in $t=2 . E\left[\pi_{2} \mid s, u_{1}, Q_{1}\right]$ denotes the expected profit on the $t=2$ transaction when it is chosen optimally given $Q_{1}$. Note that in choosing the $t=2$ transaction, the speculator maximizes the continuation profit, which is different from the profit on $t=2$ transaction. This is because feedback from price to firm value implies that the $t=2$ trade can affect the value of the position established in $t=1$. For example, if the speculator bought in $t=1$ and then bought again in $t=2$, his continuation profit is $2 V-p_{2}$, while his profit on the $t=2$ transaction is $V-p_{2}$, and his total profit across both periods is $2 \mathrm{~V}-\mathrm{p}_{1}-\mathrm{p}_{2}$.

We make the following observations regarding market prices. First, the price in $t=2$ is never negative. This is because a negative price would contradict the assumption that the firm chooses investment optimally given the information contained in the price. Second, if $Q_{1}=Q_{2}=0$, order flows reveal no information about the identity of the speculator. Then, since $\bar{V}>0$, investment will take place, and the price will be $p_{2}(0,0)=\bar{V}$. Third, prices in $t=1$ are formed to reflect the expected price in $t=2$ given the information in the order flow. This means that the price in $t=1$ is also never negative, while $p_{1}(0)$ is strictly positive.

We establish two relations regarding the pay-offs from trading strategies as a function of the underlying signals:

$$
\begin{gathered}
E\left[\pi \mid s=l, u_{1}=-1\right] \geq E\left[\pi \mid s=\varnothing, u_{1}=-1\right] \geq E\left[\pi \mid s=h, u_{1}=-1\right], \\
E\left[\pi \mid s=l, u_{1}=1\right] \leq E\left[\pi \mid s=\varnothing, u_{1}=1\right] \leq E\left[\pi \mid s=h, u_{1}=1\right] .
\end{gathered}
$$

Intuitively, (25) says that the expected profit from selling in $t=1$ (weakly) decreases as the signal about the fundamentals improves (i.e. as it moves from $s=l$ to $\varnothing$ to $h$ ). Conversely, (26) says that the expected profit from buying in $t=1$ (weakly) increases as the signal about the fundamentals improves. To see why (25) holds, note that after selling in $t=1$, the speculator can either sell, buy, or not trade in $t=2$. In the first case, his total profit will be $p_{1}+p_{2}-2 V$; in the second case, it will be $p_{1}-p_{2}$; and in the third case, it will be $p_{1}-V$. All these expressions are weakly decreasing in the value of the firm. Thus, by mimicking the strategy of the uninformed (positively informed) speculator, the negatively informed (uninformed) speculator can make a profit that is at least as high. This profit may only become higher if the negatively informed (uninformed) speculator chooses the strategy that is optimal for him. The argument behind (26) is analogous, given that after buying in $t=1$, total profits will be $2 V-p_{1}-p_{2}, V-p_{1}$, or $p_{2}-p_{1}$, if the speculator buys, does not trade, or sells in $t=2$, respectively. These profits are all weakly increasing in the value of the firm. Note 
that the inequality becomes strict if the speculator strictly prefers to buy in $t=2$ and if investment happens with positive probability afterwards. In Lemma 3, we show that the positively informed speculator strictly prefers to buy in $t=2$ after buying in $t=1$. This generates investment with positive probability since investment always happens after $Q_{1}=Q_{2}=0$. Thus, we get that the following strict inequality holds:

$$
E\left[\pi \mid s=\varnothing, u_{1}=1\right]<E\left[\pi \mid s=h, u_{1}=1\right] .
$$

Finally, we conclude this part of the proof by stating three lemmas that characterize the behaviour of speculators in a candidate equilibrium, where the uninformed speculator does not sell in $t=1$. The proofs of these lemmas appear after the proof of Proposition 3.

Lemma 2. In any candidate equilibrium, where the uninformed speculator does not sell in $t=1$, and $\bar{V}$ is sufficiently small, the following holds:

(1) The negatively informed speculator does not buy in $t=1$.

(2) When $p_{1}>0$, the negatively informed speculator does not buy in $t=2$.

(3) After $Q_{1}=0$, the negatively informed speculator always sells in $t=2$.

Lemma 3. In any candidate equilibrium, where off-the-path beliefs satisfy the intuitive criterion, the uninformed speculator does not sell in $t=1$, and $\bar{V}$ is sufficiently small, the following holds:

(1) The positively informed speculator buys in $t=2$ after an order flow of $Q_{1}$ if (a) $V^{+}>p_{1}\left(Q_{1}\right)>0$, (b) $u_{1} \in\{0,1\}$ and (c) investment occurs following $Q_{2}=0$.

(2) The positively informed speculator does not sell in $t=1$.

(3) After $Q_{1}=0$ or 1 , the positively informed speculator always buys in $t=2$. After $Q_{1}=2$, the positively informed speculator always buys in $t=2$, as long as the uninformed speculator buys in $t=1$ in equilibrium.

Lemma 4. In a candidate equilibrium, where the uninformed speculator does not sell in $t=1$, and $\bar{V}$ is sufficiently small, the uninformed speculator does not buy in $t=2$ after $Q_{1}=0$.

\section{B. Not trading vs. selling}

The expected profit of the uninformed speculator from not trading in $t=1$ is $E\left[\pi \mid s=\varnothing, u_{1}=0\right]$, which can be written as

$$
\begin{aligned}
& \frac{1}{3} E\left[\pi_{2} \mid s=\varnothing, u_{1}=0, Q_{1}=-1\right] \\
& +\frac{1}{3} E\left[\pi_{2} \mid s=\varnothing, u_{1}=0, Q_{1}=0\right] \\
& +\frac{1}{3} E\left[\pi_{2} \mid s=\varnothing, u_{1}=0, Q_{1}=1\right] .
\end{aligned}
$$

If he sells, he gets at least $\frac{1}{3}\left(p_{1}(-2)+p_{1}(-1)+p_{1}(0)\right)-\bar{V}$ on his $t=1$ transaction, and then

$$
\begin{aligned}
& \frac{1}{3} E\left[\pi_{2} \mid s=\varnothing, u_{1}=-1, Q_{1}=-1\right] \\
& +\frac{1}{3} E\left[\pi_{2} \mid s=\varnothing, u_{1}=-1, Q_{1}=0\right] \\
& +\frac{1}{3} E\left[\pi_{2} \mid s=\varnothing, u_{1}=-1, Q_{1}=-2\right],
\end{aligned}
$$

on his $t=2$ transaction. If he sells and $Q_{1}=-1$ or 0 , the profit he can make on his $t=2$ transaction is at least as high as the profit he makes after he does not trade and $Q_{1}=-1$ or 0 . If he sells and $Q_{1}=-2$, he makes at least 0 on his $t=2$ transaction. Thus, he strictly prefers $u_{1}=-1$ to $u_{1}=0$ when

$$
\frac{1}{3}\left(p_{1}(-2)+p_{1}(-1)+p_{1}(0)\right)-\bar{V}>\frac{1}{3} E\left[\pi_{2} \mid s=\varnothing, u_{1}=0, Q_{1}=1\right] .
$$

Given that prices are never negative, and taking a sufficiently small $\bar{V}$, it is sufficient to show that

$$
E\left[\pi_{2} \mid s=\varnothing, u_{1}=0, Q_{1}=1\right]<p_{1}(0) .
$$


We now characterize $p_{1}(0)$. In equilibrium, $Q_{1}=0$ can be generated by the positively informed, negatively informed, and uninformed speculator, with probabilities $\frac{\alpha}{2}, \frac{\alpha}{2}$, and $(1-\alpha)$, respectively. From Lemma 2 we know that after $Q_{1}=0$, the negatively informed speculator always sells in $t=2$. From Lemma 3 we know that after $Q_{1}=0$, the positively informed speculator always buys in $t=2$. From Lemma 4 we know that after $Q_{1}=0$, the uninformed speculator never buys in $t=2$. We use $\xi$ to denote the probability that the uninformed speculator does not trade in $t=2$ after $Q_{1}=0$. Using these results, we can characterize $t=2$ prices, conditional on $Q_{1}=0$. With probability $\frac{1}{3} \frac{\alpha}{2}, Q_{2}=2$, and the price $p_{2}(0,2)$ is given by $V^{+}$. With probability $\frac{1}{3} \frac{\alpha}{2}+\frac{1}{3}(1-\alpha) \xi, Q_{2}=1$, and the price $p_{2}(0,1)$ is given by $\frac{\frac{1}{3} \frac{\alpha}{2} V^{+}+\frac{1}{3}(1-\alpha) \xi \bar{V}}{\frac{1}{3} \frac{\alpha}{2}+\frac{1}{3}(1-\alpha) \xi}$. With probability $\frac{1}{3}, Q_{2}=0$, and the price $p_{2}(0,0)$ is given by $\bar{V}$. With probability $\frac{1}{3} \frac{\alpha}{2}+\frac{1}{3}(1-\alpha)$, $Q_{2}=-1$, and the price $p_{2}(0,-1)$ is given by 0 (because the order flow can be generated by the uninformed speculator or by the negatively informed speculator, and thus, for a sufficiently small $\bar{V}$, the investment is rejected). With probability $\frac{1}{3} \frac{\alpha}{2}+\frac{1}{3}(1-\alpha)(1-\xi), Q_{2}=-2$, and the price $p_{2}(0,-2)$ is given by $0 . p_{1}(0)$ is then a weighted average of the possible $t=2$ prices. It is given by

$$
\frac{\alpha}{3} V^{+}+\frac{1}{3}((1-\alpha) \xi+1) \bar{V}
$$

Thus, to prove (31), it is sufficient to show that

$$
E\left[\pi_{2} \mid s=\varnothing, u_{1}=0, Q_{1}=1\right]<\frac{\alpha}{3} V^{+} .
$$

Now, let us characterize $E\left[\pi_{2} \mid s=\varnothing, u_{1}=0, Q_{1}=1\right]$. If the uninformed speculator does not trade in $t=2$, his profit is 0 . If he buys, he makes a maximum profit of $\bar{V}$. Both these profits are clearly below $\frac{\alpha}{3} V^{+}$. If he sells in $t=2$ his maximum profit is $\frac{1}{3}\left(p_{2}(1,-2)+p_{2}(1,-1)+p_{2}(1,0)\right)$. Thus, to prove (33), it is sufficient to show that

$$
p_{2}(1,-2)+p_{2}(1,-1)+p_{2}(1,0)<\alpha V^{+} .
$$

From Lemma 3 we know that after $Q_{1}=1$, the positively informed speculator always buys in $t=2$. Thus, when $Q_{2}=-2$ or -1 , it is known that the positively informed speculator is not behind the trade. As a result, $p_{2}(1,-2)$ and $p_{2}(1,-1)$ are at most $\bar{V}$. Given that the uninformed speculator does not sell in $t=1$, the maximum value of $p_{2}(1,0)$ is $\frac{\alpha V^{+}+2(1-\alpha) \bar{V}}{2-\alpha}$. Thus, a sufficient condition for (34) is

$$
\frac{\alpha}{2-\alpha} V^{+}+\frac{6-4 \alpha}{2-\alpha} \bar{V}<\alpha V^{+}
$$

Since $\alpha<1$, this always holds for a sufficiently small $\bar{V}$.

\section{Not trading vs. buying}

The expected profit of the uninformed trader from not trading in $t=1$ is given by (28). If he buys, he gets at most $\bar{V}-\frac{1}{3}\left(p_{1}(0)+p_{1}(1)+p_{1}(2)\right)$ on his $t=1$ transaction, and then

$$
\begin{aligned}
& \frac{1}{3} E\left[\pi_{2} \mid s=\varnothing, u_{1}=1, Q_{1}=0\right] \\
& +\frac{1}{3} E\left[\pi_{2} \mid s=\varnothing, u_{1}=1, Q_{1}=1\right] \\
& +\frac{1}{3} E\left[\pi_{2} \mid s=\varnothing, u_{1}=1, Q_{1}=2\right]
\end{aligned}
$$

on his $t=2$ transaction. If he does not trade and $Q_{1}=1$ or 0 , the profit he can make on his $t=2$ transaction is at least as high as the profit he makes after he buys and $Q_{1}=1$ or 0 . If he does not trade and $Q_{1}=-1$, he makes at least 0 on his $t=2$ transaction. Thus, he strictly prefers $u_{1}=0$ to $u_{1}=1$ when

$$
\bar{V}-\frac{1}{3}\left(p_{1}(0)+p_{1}(1)+p_{1}(2)\right)+\frac{1}{3} E\left[\pi_{2} \mid s=\varnothing, u_{1}=1, Q_{1}=2\right]<0 .
$$

Given (32) and given that prices cannot be negative, for a sufficiently small $\bar{V}$, it is sufficient to show that

$$
E\left[\pi_{2} \mid s=\varnothing, u_{1}=1, Q_{1}=2\right]-p_{1}(2)<\frac{\alpha}{3} V^{+} .
$$

If the uninformed speculator does not trade in $t=2$ after $Q_{1}=2$, his $t=2$ profit is 0 , and the inequality clearly holds. If the uninformed speculator buys in $t=2$ after $Q_{1}=2$, his $t=2$ profit cannot exceed $\bar{V}$, and the inequality 
holds for a sufficiently small $\bar{V}$. The more interesting case is when the uninformed speculator sells in $t=2$ after $Q_{1}=2$. In this case, his $t=2$ profit is at most $\frac{1}{3}\left(p_{2}(2,0)+p_{2}(2,-1)+p_{2}(2,-2)\right)$. Thus, we need to show that

$$
\frac{1}{3}\left(p_{2}(2,0)+p_{2}(2,-1)+p_{2}(2,-2)\right)-p_{1}(2)<\frac{\alpha}{3} V^{+}
$$

From Lemma 2 we know that the negatively informed speculator does not buy in $t=1$. Thus, if the uninformed speculator buys in $t=1$ in equilibrium, $Q_{1}=2$ can result from both the positively informed and the uninformed speculator. Then, from Lemma 3, the positively informed speculator buys in $t=2$. Thus, given that $p_{1}$ is a weighted average of possible $t=2$ prices, selling in $t=2$ will push the price down, implying that the L.H.S. of (39) is at most 0 , and thus that (39) holds. \|

\section{Proof of Lemma 2.}

Part 1: By way of contradiction, suppose that the negatively informed speculator buys in $t=1$. In that period, total order flow will be 0,1 , or 2 . Since prices are either 0 or positive, and the value of the firm, conditional on $s=l$, is either 0 (if the firm does not invest) or negative (if the firm invests), he maximizes his expected profit by selling in $t=2$. As a result, the maximum total profit from buying in $t=1$ is

$$
\begin{aligned}
& \frac{1}{3}\left(E\left[p_{2} \mid Q_{1}=0, u_{2}=-1\right]-p_{1}(0)\right) \\
& \quad+\frac{1}{3}\left(E\left[p_{2} \mid Q_{1}=1, u_{2}=-1\right]-p_{1}(1)\right) \\
& \quad+\frac{1}{3}\left(E\left[p_{2} \mid Q_{1}=2, u_{2}=-1\right]-p_{1}(2)\right) .
\end{aligned}
$$

If, instead, the speculator deviates to not trading in $t=1$ and selling in $t=2$, his expected profit is

$$
\begin{aligned}
& \frac{1}{3}\left(E\left[p_{2} \mid Q_{1}=0, u_{2}=-1\right]-E\left[V \mid s=l, Q_{1}=0, u_{2}=-1\right]\right) \\
& \quad+\frac{1}{3}\left(E\left[p_{2} \mid Q_{1}=1, u_{2}=-1\right]-E\left[V \mid s=l, Q_{1}=1, u_{2}=-1\right]\right) \\
& \quad+\frac{1}{3}\left(E\left[p_{2} \mid Q_{1}=-1, u_{2}=-1\right]-E\left[V \mid s=l, Q_{1}=-1, u_{2}=-1\right]\right) .
\end{aligned}
$$

We know that prices are always 0 or positive, and firm value conditional on $s=l$ is either 0 or negative. We also know that $p_{1}(0)$ is strictly positive and that investment happens after $Q_{1}=Q_{2}=0$, generating a negative value of $V^{-}$. Thus, the sum of the first two rows in (40) is strictly smaller than the sum of the first two rows in (41). Also, the last row in (41) is at least 0 . Thus, to show that the negatively informed speculator would deviate from buying in $t=1$ to not trading, we need to show that the last row in (40) is at most 0 . That is, the profit from buying in $t=1$ and then selling after $Q_{1}=2$ cannot be strictly positive. Here, we need to distinguish between two cases. First, if, following $Q_{1}=2$, the negatively informed speculator sells with probability 1 , the expected price in equilibrium following a sell order cannot increase. Second, if, following $Q_{1}=2$, he sells with probability less than 1 , it means he is indifferent between selling and either buying or not trading. Since we already know that, conditional on $s=l$, buying or not trading cannot generate a strictly positive continuation profit, his continuation profit, and thus his total profit, cannot be strictly positive.

Part 2: From Part 1 we know that the negatively informed speculator did not buy in $t=1$. Suppose that he did not trade in $t=1$. Then, his continuation profit from buying is $E\left[V-p_{2} \mid s=l, u_{2}=1\right] \leq 0$, with strict inequality when the firm invests after some $Q_{2} \in\{0,1,2\}$. Alternatively, the continuation profit from selling is $E\left[p_{2}-V \mid s=l, u_{2}=-1\right] \geq 0$, with strict inequality if the firm invests following some $Q_{2} \in\{-2,-1,0\}$. Hence, as long as investment happens after some $Q_{2}$ (i.e. as long as $p_{1}>0$ ), selling in $t=2$ is strictly preferred over buying. Now, suppose that the negatively informed speculator sold in $t=1$. His continuation profit from buying is $-E\left[p_{2} \mid u_{2}=1\right] \leq 0$, with strict inequality when the firm invests after some $Q_{2} \in\{0,1,2\}$. Alternatively, the continuation profit from selling is $E\left[p_{2}-2 V \mid s=l\right.$, $\left.u_{2}=-1\right] \geq 0$, with strict inequality if the firm invests following some $Q_{2} \in\{-2,-1,0\}$. Hence, as before, as long investment happens after some $Q_{2}$, selling in $t=2$ is strictly preferred over buying.

Part 3: Since $p_{1}(0)>0$, we know from Part 2 that the negatively informed speculator does not buy in $t=2$ after $Q_{1}=0$. We now show that he strictly prefers to sell in $t=2$ than not to trade. Suppose that he did not trade in $t=1$. Then, his continuation profit from selling is $E\left[p_{2}-V \mid s=l, u_{2}=-1\right]$, while his continuation profit from not trading is 0 . The continuation profit from selling is strictly greater since investment happens after $Q_{2}=0$ generating a positive price and a negative value. Now, suppose that the negatively informed speculator sold in $t=1$. His continuation profit from selling is $E\left[p_{2}-2 V \mid s=l, u_{2}=-1\right]$, while his continuation profit from not trading is $-E\left[V \mid s=l, u_{2}=0\right]$. After comparing 
these expressions, we find that the continuation profit from selling is strictly greater given that investment happens after $Q_{2}=0$ generating a positive price and a negative value of $V^{-}$.

Proof of Lemma 3.

Part 1: A first step for the proof of this lemma is to show that if investment occurs after any $t=2$ order flow that is consistent with $u_{2}=-1$ (i.e. $Q_{2} \in\{-2,-1,0\}$ ), it also occurs for all order flows consistent with $u_{2}=1$ (i.e. $Q_{2} \in\{0,1,2\}$ ).

To see this note that when investment occurs after some order flow consistent with $u_{2}=-1$, the negatively informed speculator has a strict incentive to sell in $t=2$. If he has a short position (no position), selling generates a continuation profit of $E\left[p_{2}-2 V \mid s=l, u_{2}=-1\right]\left(E\left[p_{2}-V \mid s=l, u_{2}=-1\right]\right)$, whereas not trading generates a continuation profit of $E\left[-V \mid s=l, u_{2}=0\right](0)$. The continuation profit from selling is strictly greater given that investment sometimes occurs after he sells, generating a positive price and a negative value of $V^{-}$. Then, given that the negatively informed speculator always sells, an order flow of 1 or 2 cannot be generated by the negatively informed speculator. Investment must therefore always occur after such order flows. (This is unless $Q_{2} \in\{1,2\}$ is off the equilibrium path and the market maker and the manager attach a sufficiently high probability to the deviation being due to the negatively informed speculator. Such a belief, however, violates the intuitive criterion since the negatively informed speculator strictly prefers to sell regardless of his $t=1$ position and the off-the-path beliefs, while there exist off-the-path beliefs under which the positively informed speculator would be better off from deviating to buying.) The probability that an order flow of 0 is generated by the negatively informed speculator is not higher than the probability that an order flow of -2 or -1 was generated by him. Thus, if investment happens after an order flow of -2 or -1 , it must happen after an order flow of 0 .

Based on this, we can now prove that the positively informed speculator strictly prefers to buy in $t=2$ after he acquired a long position in $t=1$, and $p_{1}$ was different from 0 or $V^{+}$. Buying in $t=2$ yields a continuation profit of $E\left[2 V-p_{2} \mid s=h, u_{2}=1\right]$; not trading yields a continuation profit of $E\left[V \mid s=h, u_{2}=0\right]$; and selling yields a continuation profit of $E\left[p_{2} \mid u_{2}=-1\right]$. Thus, buying is strictly better than selling if $2 E\left[V \mid s=h, u_{2}=1\right]-E\left[p_{2} \mid u_{2}=1\right]-$ $E\left[p_{2} \mid u_{2}=-1\right]>0$. If investment happens after any $Q_{2} \in\{-2,-1,0\}$, it must happen after all $Q_{2} \in\{0,1,2\}$. Thus, $E\left[V \mid s=h, u_{2}=1\right]=V^{+}$, while both $E\left[p_{2} \mid u_{2}=1\right]$ and $E\left[p_{2} \mid u_{2}=-1\right]$ must be smaller than $V^{+}$, since $p_{1}$ was lower than $V^{+}$, so $p_{2}\left(Q_{2}=0\right)$ must also be below $V^{+}$. Thus, the above expression is positive. If investment never happens after $u_{2}=-1$, it must happen sometime after $u_{2}=1$ (since $p_{1}$ was higher than 0 ). Then, $E\left[p_{2} \mid u_{2}=-1\right]=0$, while $E\left[V \mid s=h, u_{2}=1\right]>0$, so the above expression is positive. Similarly, buying is preferable to not trading if $2 E\left[V \mid s=h, u_{2}=1\right]-E\left[p_{2} \mid u_{2}=1\right]-E\left[V \mid s=h, u_{2}=0\right]>0$. Using similar arguments and the fact that investment always happens after $Q_{2}=2$ (since the negatively informed speculator does not buy in $t=2$ ) we can show that this indeed holds.

Now, let us analyse the choice of the positively informed trader in $t=2$ after he did not trade in $t=1$, and 0 $<p_{1}<V^{+}$. Buying in $t=2$ yields a continuation profit of $E\left[V-p_{2} \mid s=h, u_{2}=1\right]$; not trading yields a continuation profit of 0 ; and selling yields a continuation profit of $E\left[p_{2}-V \mid s=h, u_{2}=-1\right]$. Using the above arguments, we know that buying is strictly better than selling and not trading if investment happens at some $Q_{2}$ consistent with $u_{2}=-1$ (for example, $Q_{2}=0$ ).

Part 2: We show that there cannot be an equilibrium, in which the positively informed speculator sells in $t=1$ and the uninformed speculator does not. Suppose the positively informed speculator sells in $t=1$. This implies that $E\left[\pi \mid s=h, u_{1}=-1\right] \geq E\left[\pi \mid s=h, u_{1}=1\right]$. Then, by (25), (26), and (27), the uninformed speculator strictly prefers selling to buying in $t=1$. We now show that in such an equilibrium, the uninformed speculator would strictly prefer to sell than not to trade in $t=1$. The maximum total profit for the positively informed speculator from $u_{1}=-1$ is $\frac{1}{3}\left(p_{1}(0)+p_{1}(-1)+p_{1}(-2)\right)$. If instead $u_{1}=0$, he can buy in $t=2$, and, since investment always happens after $Q_{1}=Q_{2}=0$ (with a price of $\bar{V}$ ), guarantee an expected profit of at least $\frac{1}{9}\left(V^{+}-\bar{V}\right)$. Since the positively informed speculator sells in $t=1$, we know that

$$
p_{1}(0)+p_{1}(-1)+p_{1}(-2) \geq \frac{1}{3}\left(V^{+}-\bar{V}\right) .
$$

If the uninformed speculator does not trade in $t=1, Q_{1}$ will be $-1,0$, or 1 . For each one of these realizations, he makes some profit $\pi_{2}$ on his $t=2$ transaction. If the uninformed speculator sells in $t=1, Q_{1}$ will be $-2,-1$, or 0 . Thus, by selling in $t=1$, he can replicate the $t=2$ profit he makes after not trading when $Q_{1}$ is either -1 , or 0 . In addition, he gets the profit on his $t=1$ transaction, which is at least $\frac{1}{3}\left(p_{1}(0)+p_{1}(-1)+p_{1}(-2)\right)-\bar{V}$. As a result, his profit from selling in $t=1$ is strictly greater than his profit from not trading if

$$
p_{1}(0)+p_{1}(-1)+p_{1}(-2)>3 \bar{V}+E\left[\pi_{2} \mid s=\varnothing, u_{1}=0, Q_{1}=1\right] .
$$

Given (42), for a sufficiently small $\bar{V}$, it is sufficient to show that

$$
E\left[\pi_{2} \mid s=\varnothing, u_{1}=0, Q_{1}=1\right]<\frac{1}{3} V^{+} .
$$

(C) 2008 The Review of Economic Studies Limited 
If the uninformed speculator does not trade in $t=2$, his total profit his 0 , which is clearly below $\frac{1}{3} V^{+}$. If he buys, he pays a price, and gets an asset with a maximum value of $\bar{V}$ (conditional on his information), so for a sufficiently small $\bar{V}$, his profit is below $\frac{1}{3} V^{+}$. If the uninformed speculator sells in $t=2$ his maximum expected profit is $\frac{1}{3}\left(p_{2}(1,0)+\right.$ $\left.p_{2}(1,-1)+p_{2}(1,-2)\right)$. Note that $Q_{1}=1$ is consistent with a positively informed speculator who either bought or did not trade in $t=1$. We know that the positively informed speculator always buys in $t=2$ after buying in $t=1$. If he did not trade in $t=1$, we need to distinguish between the case in which he strictly prefers to buy in $t=2$ and the case in which he does not. In the second case, we know from Part 1 of this lemma that investment does not happen after any $Q_{2}$ consistent with $u_{2}=-1$. Thus, $p_{2}(1,0)=p_{2}(1,-1)=p_{2}(1,-2)=0$, and the uninformed speculator makes no profit from selling in $t=2$. If the positively informed speculator strictly prefers to buy in $t=2$, both $p_{2}(1,-1)$ and $p_{2}(1,-2)$ cannot be greater than $\bar{V}$, as $Q_{2}=-1$ and $Q_{2}=-2$ are inconsistent with the positively informed speculator. Moreover, $p_{2}(1,0)$ has to be below $V^{+}$, since $Q_{1}=1$ and $Q_{2}=0$ is consistent with the uninformed speculator when he does not sell in $t=1$. Thus, $\frac{1}{3}\left(p_{2}(1,0)+p_{2}(1,-1)+p_{2}(1,-2)\right)<\frac{1}{3}\left(V^{+}+2 \bar{V}\right)$. This implies that, for a sufficiently small $\bar{V}$, (44) holds.

Part 3: This follows directly from the first two parts of the lemma and the fact (which follows from the investment strategies proven above) that after $Q_{1} \in\{0,1,2\}$ and $Q_{2}=0$ the firm invests.

Proof of Lemma 4. Given that the speculator is uninformed, the value of the firm is either $\bar{V}$ or 0 . Thus, for a sufficiently small $\bar{V}$, the uninformed speculator chooses his $t=2$ transaction to maximize the $t=2$ profit (i.e. the effect of the transaction on the value of his existing position is negligible). We know from Lemmas 2 and 3 that the negatively informed speculator always sells and the positively informed speculator always buys after $Q_{1}=0$. Thus, if the uninformed speculator buys after $Q_{1}=0$, the price he pays at $Q_{2}=1$ and $Q_{2}=2$ is a weighted average between $\bar{V}$ and $V^{+}$. Since the value of the asset, given his information, does not exceed $\bar{V}$, he makes a loss on his $t=2$ transaction. Thus, he prefers not to buy.

Proof of Proposition 4. Suppose that the uninformed speculator buys in $t=1$. Since prices are either 0 or positive, and the expected value of the firm, conditional on $s=\varnothing$ and $\bar{V}<0$ is either 0 (if the firm does not invest) or negative (if the firm invests), he cannot make a strictly positive profit unless he sells in $t=2$. Selling in $t=2$ generates a total profit of

$$
\begin{aligned}
& \frac{1}{3}\left(E\left[p_{2} \mid Q_{1}=0, u_{2}=-1\right]-p_{1}(0)\right)+\frac{1}{3}\left(E\left[p_{2} \mid Q_{1}=1, u_{2}=-1\right]-p_{1}(1)\right) \\
& \quad+\frac{1}{3}\left(E\left[p_{2} \mid Q_{1}=2, u_{2}=-1\right]-p_{1}(2)\right) .
\end{aligned}
$$

First, note that the third term of (45) cannot be strictly positive. If it is strictly positive, then $E\left[p_{2} \mid Q_{1}=2\right.$, $\left.u_{2}=-1\right]>0$. Given that $\bar{V}<0$ and that at $Q_{1}=2$ the speculator has a long position, this implies that the uninformed speculator and the negatively informed speculator strictly prefer to sell in $t=2$. As a result, selling pushes the price weakly below $p_{1}(2)$, and so $E\left[p_{2} \mid Q_{1}=2, u_{2}=-1\right]-p_{1}(2) \leq 0$.

Now, for the uninformed speculator to make a positive profit, either $E\left[p_{2} \mid Q_{1}=0, u_{2}=-1\right]-p_{1}(0)>0$ or $E\left[p_{2} \mid Q_{1}=1, u_{2}=-1\right]-p_{1}(1)>0$, or both, must hold. This implies that investment happens after some nodes following $Q_{1}=0$ and/or $Q_{1}=1$, and thus $p_{1}(0)$ and/or $p_{1}(1)$ is strictly positive. But then, the uninformed speculator is strictly better off deviating to not trading in $t=1$ and selling in $t=2$, in which case he makes a profit of

$$
\begin{aligned}
& \frac{1}{3}\left(E\left[p_{2} \mid Q_{1}=0, u_{2}=-1\right]-E\left[V \mid s=\varnothing, Q_{1}=0, u_{2}=-1\right]\right) \\
& \quad+\frac{1}{3}\left(E\left[p_{2} \mid Q_{1}=1, u_{2}=-1\right]-E\left[V \mid s=\varnothing, Q_{1}=1, u_{2}=-1\right]\right) \\
& \quad+\frac{1}{3}\left(E\left[p_{2} \mid Q_{1}=-1, u_{2}=-1\right]-E\left[V \mid s=\varnothing, Q_{1}=-1, u_{2}=-1\right]\right) .
\end{aligned}
$$

This is strictly greater than (45) because the third row in (46) is at least 0 , the last term in (45) is at most 0 , the expected value is at most 0 , and $p_{1}(0)$ and/or $p_{1}(1)$ is strictly positive.

Proof of Proposition 5. Suppose that there are $N$ arbitrageurs. If all the arbitrageurs never trade in equilibrium, then all other players are in a game that is identical to the one solved for in Proposition 2. Hence, to show that the equilibrium in Proposition 2 is still an equilibrium when the arbitrageurs are present, we only need to prove that the $i$-th arbitrageur's best response to the speculator's and the firm's strategies is not to trade at any node of the game (knowing 
that the other $N-1$ arbitrageurs are not trading in equilibrium). To ease the exposition, in the remainder of the proof we will simply refer to the $i$-th arbitrageur as "the arbitrageur".

Denote by $b_{t}$ the arbitrageur's trade in date $t$. Suppose that when the market maker observes an order flow $Q_{t}=3$ or -3 , he sets the price as if the order flow had been $Q_{t}=2$ or -2 , respectively. This is supported by the off-the-path belief that the deviation can be attributed to the arbitrageur who bought (if $Q_{t}=3$ ) or sold (if $Q_{t}=-3$ ). We now calculate the expected trading profits of the arbitrageur if he buys, sells or does not trade in $t=1$, and show that his best response is not to trade at any node of the game.

A. $b_{1}=1$ : Given that $b_{1}=1$, it follows that $Q_{1} \in\{-1,0,1,2,3\}$.

If $Q_{1}=2$ or $3, p_{1}$ and $p_{2}$ are set at $V^{+}$regardless of $t=2$ order flow, and thus the arbitrageur makes at most a profit of 0 .

If $Q_{1}=-1, p_{1}$ and $p_{2}$ are set at 0 regardless of $t=2$ order flow. Moreover, the firm ends up not investing, so its value is also 0 . Thus, the arbitrageur makes a profit of 0 .

If $Q_{1}=0$, the speculator must have submitted either -1 or 0 in $t=1$. This implies that the speculator is either negatively informed or uninformed, and thus the value of the firm is at most $\bar{V}$. Given that the arbitrageur paid $p_{1}(0)>\bar{V}$, he makes a strictly negative profit on his $t=1$ trade. Since the speculator does not detect the deviation by the arbitrageur, he trades -1 or 0 in $t=2$. Then, if the arbitrageur does not trade in $t=2$, his total profit remains strictly negative. If he sells in $t=2$, he gets a price of at most $\bar{V}$, and makes a strictly negative total profit. If he buys in $t=2$, he either pays a price of 0 for an asset that ends up being worth 0 (since no investment happens), or he pays a price of at least $\bar{V}$ for an asset that is worth no more than $\bar{V}$. Thus, his total profit remains strictly negative.

If $Q_{1}=1$, the arbitrageur's posterior over the speculator's signal is $\operatorname{Pr}\left(s=h \mid Q_{1}=1, b_{1}=1\right)=\operatorname{Pr}\left(s=l \mid Q_{1}=1\right.$, $\left.b_{1}=1\right)=\frac{\alpha}{2}$ and $\operatorname{Pr}\left(s=\varnothing \mid Q_{1}=1, b_{1}=1\right)=1-\alpha$. The speculator can detect the deviation only if $u_{1}=-1$ and $s \in\{\varnothing, l\}$. Suppose he believes at this node that the arbitrageur will not trade in $t=2$ (below we show that this would be the arbitrageur's optimal trade at this node). In this case, based on arguments similar to those in the proof of Proposition 2, both the uninformed and the negatively informed speculator would like to sell again in $t=2$. Thus, overall, if $s=h$ then $u_{2}=1$, and if $s=l$ or $\varnothing$ then $u_{2}=-1$. Then, if $b_{2}=1$, the total trading profit for the arbitrageur is

$$
-p_{1}(1)+\frac{\alpha}{2} V^{+}+\frac{1}{3} \frac{\alpha}{2}\left(4 V^{-}-V^{+}-p_{2}(1,0)\right)+\frac{1}{3}(1-\alpha)\left(4 \bar{V}-V^{+}-p_{2}(1,0)\right) .
$$

This can be rewritten as

$$
-p_{1}(1)+\bar{V}+\frac{1}{3} \frac{\alpha}{2}\left(V^{-}-V^{+}-p_{2}(1,0)\right)+\frac{1}{3}(1-\alpha)\left(\bar{V}-V^{+}-p_{2}(1,0)\right)<0
$$

If $b_{2}=0$, the total trading profit for the arbitrageur is

$$
-p_{1}(1)+\frac{\alpha}{2} V^{+}+\frac{1}{3} \frac{\alpha}{2} V^{-}+\frac{1}{3}(1-\alpha) \bar{V}
$$

Using the value of $p_{1}(1)$ from the proof of Proposition 2, this is strictly negative when

$$
\frac{\alpha}{\alpha(1+\mu)+2(1-\alpha) \mu} V^{+}-\frac{\alpha}{2} V^{+}+\frac{1}{3}\left(\alpha V^{-}+2(1-\alpha) \bar{V}\right)\left(\frac{\mu}{\alpha(1+\mu)+2(1-\alpha) \mu}-\frac{1}{2}\right) \geq 0
$$

which holds whenever (4) is satisfied. If $b_{2}=-1$, the total trading profit for the arbitrageur is

$$
-p_{1}(1)+\frac{1}{3} \frac{\alpha}{2}\left(V^{+}+p_{2}(1,0)\right)
$$

Again, using equilibrium prices this is strictly negative. Thus, from (48), (50), and (51), the arbitrageur makes a strictly negative profit after $b_{1}=1$ and $Q_{1}=1$ if the speculator believes at this node that the arbitrageur will not trade in $t=2$. Indeed, comparing (47), (49), and (51), the arbitrageur is better off not trading in $t=2$ at this node, so this belief is consistent.

Hence, the arbitrageur expects a strictly negative profit following $b_{1}=1$, and therefore prefers never to trade than to buy in $t=1$.

B. $b_{1}=0$ : Given that $b_{1}=0$, it follows that $Q_{1} \in\{-2,-1,0,1,2\}$.

If $Q_{1}=-2,-1$, or 2 , then, regardless of $t=2$ order flows, $p_{2}$ is equal to the value of the firm (either 0 or $V^{+}$). Thus, the arbitrageur makes a profit of 0 from trading, so it is optimal for him not to trade. 
If $Q_{1}=0$, then buying in $t=2$ generates the following profit for the arbitrageur:

$$
\begin{aligned}
& \frac{\alpha}{2}\left(V^{+}-\frac{2}{3} V^{+}-\frac{1}{3} p_{2}(0,1)\right)+(1-\alpha) \mu\left(\bar{V}-\frac{1}{3}\left(V^{+}+p_{2}(0,1)+\bar{V}\right)\right) \\
& +\frac{1}{3}(1-\alpha)(1-\mu)\left(\bar{V}-p_{2}(0,1)\right)+\frac{1}{3} \frac{\alpha}{2}\left(2 V^{-}-\bar{V}-p_{2}(0,1)\right) .
\end{aligned}
$$

This can be rewritten as

$$
\begin{aligned}
& \frac{\alpha}{2}\left(\bar{V}-\frac{1}{3} V^{+}-\frac{2}{3} p_{2}(0,1)\right)+(1-\alpha) \mu\left(\bar{V}-\frac{1}{3}\left(V^{+}+p_{2}(0,1)+\bar{V}\right)\right) \\
& \quad+\frac{1}{3}(1-\alpha)(1-\mu)\left(\bar{V}-p_{2}(0,1)\right)<0 .
\end{aligned}
$$

Selling in $t=2$ generates the following profit:

$$
\frac{1}{3} \frac{\alpha}{2}\left(p_{2}(0,1)+\bar{V}-2 V^{+}\right)<0 .
$$

Thus, profits are strictly negative if the arbitrageur buys or sells following $Q_{1}=0$, so he would prefer not to trade. If $Q_{1}=1$, then buying in $t=2$ generates the following profit for the arbitrageur:

$$
\frac{2(1-\alpha) \mu}{\alpha(1+\mu)+2(1-\alpha) \mu}\left(\frac{2}{3} \bar{V}-\frac{1}{3} V^{+}-\frac{1}{3} p_{2}(1,0)\right)+\frac{\alpha \mu}{\alpha(1+\mu)+2(1-\alpha) \mu}\left(\frac{2}{3} V^{-}-\frac{1}{3} V^{+}-\frac{1}{3} p_{2}(1,0)\right)<0 .
$$

Selling in $t=2$ generates the following profit:

$$
\frac{\alpha}{\alpha(1+\mu)+2(1-\alpha) \mu}\left(\frac{1}{3}\left(V^{+}+p_{2}(1,0)\right)-\frac{2}{3} V^{+}\right)<0
$$

Thus, profits are strictly negative if the arbitrageur buys or sells following $Q_{1}=1$, so he would prefer not to trade.

C. $b_{1}=-1$ : Given that $b_{1}=-1$, it follows that $Q_{1} \in\{-3,-2,-1,0,1\}$.

If $Q_{1}=-3,-2$, or $-1, p_{1}$ and $p_{2}$ are equal to 0 regardless of $t=2$ order flow. Moreover, the firm ends up not investing, so its value is also 0 . Thus, the arbitrageur makes a profit of 0 .

If $Q_{1}=1$, the speculator must have submitted $u_{1}=1$, and thus is positively informed. If the arbitrageur then buys or does not trade in $t=2$, his total profit is $p_{1}(1)-V^{+}$. If he sells in $t=2$, his total profit is

$$
p_{1}(1)+\frac{1}{3} p_{2}(1,0)-V^{+}
$$

Thus, in this node, he chooses to sell in $t=2$, and his total profit is given by (57). We will consider this in determining the total expected profit that the arbitrageur makes by selling in $t=1$.

If $Q_{1}=0$, then buying in $t=2$ generates the following profit for the arbitrageur:

$$
p_{1}(0)-\frac{1}{3} \frac{\alpha\left(2 V^{+}+p_{2}(0,1)\right)+2(1-\alpha) \mu\left(V^{+}+\bar{V}+p_{2}(0,1)\right)+\alpha \mu\left(\bar{V}+p_{2}(0,1)\right)}{\alpha(1+\mu)+2(1-\alpha) \mu} .
$$

Not trading in $t=2$ generates the following profit:

$$
p_{1}(0)-\frac{1}{3} \frac{3 \alpha V^{+}+4(1-\alpha) \mu \bar{V}+\alpha \mu V^{-}}{\alpha(1+\mu)+2(1-\alpha) \mu} .
$$

This is at least as high as the profit from buying, so we can ignore the possibility that the arbitrageur buys in $t=2$ in this node. Selling in $t=2$ generates the following profit:

$$
p_{1}(0)+\frac{1}{3} \frac{\alpha\left(p_{2}(0,1)+\bar{V}-4 V^{+}\right)-2(1-\alpha) \mu \bar{V}}{\alpha(1+\mu)+2(1-\alpha) \mu} .
$$

Now, suppose the arbitrageur chooses $b_{2}=0$ after $b_{1}=-1$ and $Q_{1}=0$. Then, the total expected profit from choosing $b_{1}=-1$ is given by

$$
\frac{1}{3} \frac{\alpha}{2}\left(p_{1}(1)+\frac{1}{3} p_{2}(1,0)-V^{+}\right)+\frac{1}{3}\left(\frac{\alpha}{2}(1+\mu)+(1-\alpha) \mu\right) p_{1}(0)-\frac{1}{18}\left(3 \alpha V^{+}+4(1-\alpha) \mu \bar{V}+\alpha \mu V^{-}\right) .
$$


If the equilibrium is in mixed strategies $(\mu>0)$, then we know that $p_{1}(0)=\frac{1}{3} p_{2}(1,0)$. From $(61)$, profits are negative if

$$
\frac{\alpha}{2}\left(p_{1}(1)-V^{+}\right)<\frac{1}{3}\left(\alpha V^{+}+(1-\alpha) \mu \bar{V}-\frac{\alpha}{2} p_{2}(1,0)\right)
$$

This always holds. If $\mu=0$, (61) is negative if

$$
\frac{1}{3}\left(\bar{V}+\alpha V^{+}+V^{+}\right)<V^{+}
$$

which is always true.

Suppose the arbitrageur chooses $b_{2}=-1$ after $b_{1}=-1$ and $Q_{1}=0$. Then, the total expected profit from choosing $b_{1}=-1$ is given by

$$
\frac{1}{3} \frac{\alpha}{2}\left(p_{1}(1)+\frac{1}{3} p_{2}(1,0)-V^{+}\right)+\frac{1}{3}\left(\frac{\alpha}{2}(1+\mu)+(1-\alpha) \mu\right) p_{1}(0)+\frac{1}{18}\left(\alpha\left(p_{2}(0,1)+\bar{V}-4 V^{+}\right)-2(1-\alpha) \mu \bar{V}\right) .
$$

If the equilibrium is in mixed strategies this is negative if

$$
\left(p_{1}(1)-V^{+}\right)+\frac{1}{3}\left(p_{2}(1,0)-V^{+}\right)+\frac{1}{3} \mu V^{-}+\frac{1}{3}\left(p_{2}(0,1)+\bar{V}-2 V^{+}\right)<0,
$$

which is always true. If the equilibrium is in pure strategies, that is, $\mu=0$, then (64) is negative if

$$
\bar{V}-\left(1-\frac{\alpha}{2}\right) V^{+}<0
$$

which is always true.

Hence, the arbitrageur expects a strictly negative profit following $b_{1}=-1$, and therefore prefers never to trade than to sell in $t=1$.

Proof of Proposition 6. We need to show that if $A^{+}$is sufficiently large, noise traders always choose to submit orders $n_{t=g}=-z_{g}$. Once we have shown that, it follows directly that the previously derived equilibrium strategies continue to be part of the equilibrium with endogenous noise traders.

Suppose $z_{g}=0$. The expected utility for the noise trader from not trading is 0 . The expected utility when submitting a buy or a sell order is negative. This is because of two reasons. First, trading leaves the noise trader with a position that exposes him to risk, which decreases his utility. Second, when buying (selling) without information, the noise trader pushes the price weakly above (below) the expected value of the asset. Thus, he makes a negative or 0 trading profit. As a result, the noise trader chooses not to trade: $n_{t=g}=0$.

Suppose $z_{g}=-1$. If $n_{t=g}=0$, the noise trader gets an expected utility of

$$
E\left[U\left(w_{g}\right) \mid n_{t=g}=0, z_{g}=-1\right]=-\frac{A^{+}}{2} \Delta \rho .
$$

Here, $\frac{A^{+}}{2} \Delta \rho$ represents the utility loss due to the exposure to risk. If $n_{t=g}=-1$, the noise trader increases his risk exposure, and makes an expected trading loss, so this is clearly suboptimal for him. If $n_{t=g}=1$, the noise trader gets an expected utility of

$$
\begin{aligned}
E\left[U\left(w_{g}\right) \mid n_{t=g}=1, z_{g}=-1\right]= & \rho^{-} E\left(\min \left\{V(\omega, k)-p_{t=g}, 0\right\} \mid n_{t=g}=1\right) \\
& +\rho^{+} E\left(\max \left\{V(\omega, k)-p_{t=g}, 0\right\} \mid n_{t=g}=1\right) .
\end{aligned}
$$

Since this expression is finite and constant in $A$, for a sufficiently large $A^{+}$, the noise trader clearly prefers $n_{t=g}=1$ over $n_{t=g}=0$.

A similar argument shows that when $z_{g}=1$, for a sufficiently large $A^{+}$, the noise trader prefers $n_{t=g}=-1$.

Acknowledgements. We would like to thank Oliver Board, Qi Chen, James Dow, Simon Gervais, Gary Gorton, Bruce Grundy, Robert Hauswald, Pete Kyle, Alan Morrison, Jeremy Stein, Oren Sussman, Sheridan Titman, the editor (Juuso Välimäki), and three anonymous referees for helpful discussions and comments. We would also like to thank seminar participants at Cass Business School, Duke University, the Federal Reserve Bank of Philadelphia, the Federal Reserve Bank of Richmond, HEC Paris, Lancaster University, London Business School, London School of Economics, Nuffield College, Tel Aviv University, the University of Amsterdam, the University of Wisconsin, and participants at the 
following conferences: The Oxford Finance Summer Symposium, 2002, the EFA Annual Meetings, Berlin 2002, the AFA Annual Meetings, Washington DC 2003, the Fifth Texas Finance Festival, San Antonio 2003, a Cowles Foundation Conference on Coordination Games, New Haven 2005, and the SED winter meeting, Boston 2006. The second author would like to thank the Fuqua School of Business, where part of this research project was carried out, for their kind hospitality. All remaining errors are ours.

\section{REFERENCES}

ALLEN, F. and GALE, D. (1992), “Stock Price Manipulation”, Review of Financial Studies, 5, 503-529.

ALLEN, F. and GORTON, G. (1992), "Stock Price Manipulation, Market Microstructure and Asymmetric Information”, European Economic Review, 36, 624-630.

ATTARI, M., BANERJEE, S. and NOE, T. (2006), "Crushed by a Rational Stampede: Strategic Share Dumping and Shareholder Insurrections", Journal of Financial Economics, 79, 181-222.

AVERY, C. and ZEMSKY, P. (1998), "Multidimensional Uncertainty and Herd Behavior in Financial Markets", American Economic Review, 88, 724-748.

BAGNOLI, M. and LIPMAN, B. (1996), "Stock Price Manipulation through Takeover Bids", Rand Journal of Economics, 27, 124-147.

BAKER, M., STEIN, J. and WURGLER, J. (2003), "When Does the Market Matter? Stock Prices and the Investment of Equity-Dependent Firms", Quarterly Journal of Economics, 118, 969-1006.

BENABOU, R. and LAROQUE, G. (1992), "Using Privileged Information to Manipulate Markets: Insiders, Gurus, and Credibility", Quarterly Journal of Economics, 107, 921-958.

BENVENISTE, L. and SPINDT, P. A. (1989), "How Investment Bankers Determine the Offer Price and Allocation of New Issues", Journal of Financial Economics, 24, 343-362.

BENVENISTE, L. and WILHELM, W. (1990), "A Comparative Analysis of IPO Proceeds under Alternative Regulatory Environments", Journal of Financial Economics, 28, 173-207.

BIAIS, B., BOSSAERTS, P. and ROCHET, J.-C. (2002), "An Optimal IPO Mechanism", Review of Economic Studies, 69, 117-146.

BIAIS, B. and HILLION, P. (1994), "Insider and Liquidity Trading in Stock and Options Markets", Review of Financial Studies, 7, 743-780.

BRUNNERMEIER, M. (2005), "Information Leakage and Market Efficiency", Review of Financial Studies, 18, 417-457.

CHAKRABORTY, A. and YILMAZ, B. (2004a), "Informed Manipulation", Journal of Economic Theory, 114, $132-152$.

CHAKRABORTY, A. and YILMAZ, B. (2004b), "Manipulation in Market Order Models", Journal of Financial Markets, 7, 187-206.

CHEN, Q., GOLDSTEIN, I. and JIANG, W. (2007), "Price Informativeness and Investment Sensitivity to Stock Price", Review of Financial Studies, 20, 619-650.

CHEUNG, Y. and CHINN, M. (2001), "Currency Traders and Exchange Rate Dynamics: A Survey of the U.S. Market" (NBER Working Paper Nos. 7416 and 7417, National Bureau of Economic Research).

CORSETTI, G., DASGUPTA, A., MORRIS, S. and SHIN, H. S. (2004), "Does One Soros Make a Difference? A Theory of Currency Crisis with Large and Small Traders", Review of Economic Studies, 71, 87-114.

CORSETTI, G., PESENTI, P. and ROUBINI, N. (2002), "The Role of Large Players in Currency Crises", in S. Edwards and J. Frankel (eds.) Preventing Currency Crises in Emerging Markets (Chicago, IL: University of Chicago Press) 197-258.

DESAI, H., RAMESH, K., THIAGARAJAN, S. R. and BALACHANDRAN, B. V. (2002), "An Investigation of the Informational Role of Short Interest in the NASDAQ Market", Journal of Finance, 57, 2263-2287.

DOW, J. (1998), “Arbitrage, Hedging and Financial Innovation”, Review of Financial Studies, 11, 739-755.

DOW, J. and GORTON, G. (1997), "Stock Market Efficiency and Economic Efficiency: Is there a Connection?", Journal of Finance, 52, 1087-1129.

DOW, J. and RAHI, R. (2003), "Informed Trading, Investment, and Economic Welfare", Journal of Business, 76, $430-454$.

DURNEV, A., MORCK, R. and YEUNG, B. (2004), "Value Enhancing Capital Budgeting and Firm-Specific Stock Return Variation", Journal of Finance, 59, 65-105.

FOSTER, D. and VISWANATHAN, S. (1990), "A Theory of Interdog Variations in Volume, Variance, and Trading Costs in Securities Markets", Review of Financial Studies, 3, 593-624.

GERARD, B. and NANDA, V. (1993), "Trading and Manipulation Around Seasoned Equity Offerings", Journal of Finance, 48, 213-245.

GUEMBEL, A. (2005), "Should Short-Term Speculators be Taxed, or Subsidised?”, Annals of Finance, 1 (3), $327-348$.

HAYEK, F. A. (1945), "The Use of Knowledge in Society", American Economic Review, 35, 519-530.

HIRSHLEIFER, D., SUBRAHMANYAM, A. and TITMAN, S. (2006), "Feedback and the Success of Irrational Investors", Journal of Financial Economics, 81, 311-338.

JARROW, R. (1992), "Market Manipulation, Bubbles, Corners, and Short Squeezes", Journal of Financial and Quantitative Analysis, 27, 311-336.

KHANNA, N. and SONTI, R. (2004), "Value Creating Stock Manipulation: Feedback Effect of Stock Prices on Firm Value", Journal of Financial Markets, 7, 237-270.

KUMAR, P. and SEPPI, D. (1992), "Futures Manipulation with 'Cash Settlement”, , Journal of Finance, 47, $1485-1502$.

(C) 2008 The Review of Economic Studies Limited 
KYLE, A. (1985), "Continuous Auctions and Insider Trading”, Econometrica, 53, 1315-1336.

LELAND, H. (1992), "Insider Trading: Should it be Prohibited?", Journal of Political Economy, 100, 859-887.

LUO, Y. (2005), "Do Insiders Learn from Outsiders? Evidence from Mergers and Acquisitions", Journal of Finance, 60, 1951-1982.

MORRIS, S. and SHIN, H. (1998), "Unique Equilibrium in a Model of Self-Fulfilling Currency Attacks", American Economic Review, 88, 587-597.

OTTAVIANI, M. and SORENSEN, P. N. (2007), "Outcome Manipulation in Corporate Prediction Markets", Journal of the European Economic Association, Papers and Proceedings, 5, 554-563.

ROCK, K. (1986), "Why New Issues are Underpriced”, Journal of Financial Economics, 15, 187-212.

SOROS, G. (1994), The Alchemy of Finance (New York: John Wiley).

SPIEGEL, M. and SUBRAHMANYAM, A. (1992), "Informed Speculation and Hedging in a Noncompetitive Securities Market”, Review of Financial Studies, 5, 307-329.

SUBRAHMANYAM, A. and TITMAN, S. (1999), "The Going-Public Decision and the Development of Financial Markets", Journal of Finance, 54, 1045-1082.

SUBRAHMANYAM, A. and TITMAN, S. (2001), "Feedback from Stock Prices to Cash Flows", Journal of Finance, 56, 2389-2413.

SUTTON, J. (1991), Sunk Costs and Market Structure (Cambridge, MA: MIT Press).

VAN BOMMEL, J. (2003), "Rumors”, Journal of Finance, 58, 1499-1520.

VILA, J.-L. (1989), “Simple Games of Market Manipulation”, Economics Letters, 29, 21-26.

VITALE, P. (2000), "Speculative Noise Trading and Manipulation in the Foreign Exchange Market", Journal of International Money and Finance, 19, 689-712. 